SAND98-0898 • UC-404,406,410,426,704,715

Unlimited Release

Printed April 1998

\title{
A Compact, Repetitive Accelerator for Military and Industrial Applications
}

F. J. Zutavern, M. W. O'Malley, M. H. Ruebuish, L. F. Rinehart, G. M. Loubriel, S. R. Babcock, and G. J. Denison.

\section{Prepared by}

Sandia National Laboratories

Albuquerque, New Mexico 87185-1153 and Livermore, California 94550

Sandia is a multiprogram laboratory operated by Sandia Corporation, a Lockheed Martin Company, for the United States Department of Energy under Contract DE-AC04-94AL85000.

Approved for public release; further dissemination unlimited.
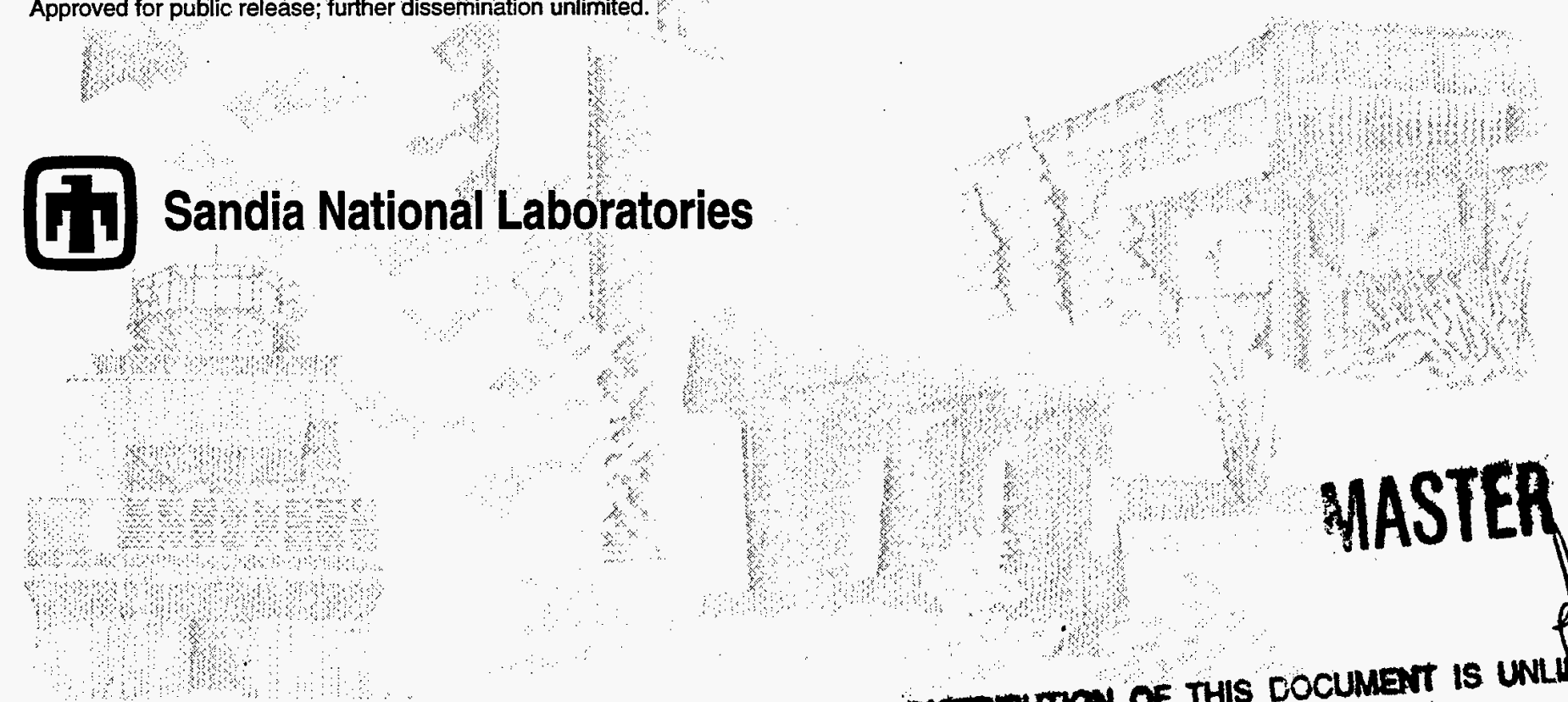

\section{MAY 27 pas8 \\ Q STI \\ ECEIVED}


Issued by Sandia National Laboratories, operated for the United States Department of Energy by Sandia Corporation.

NOTICE: This report was prepared as an account of work performed by an agency of the United States Government. Neither the United States Government, nor any agency thereof, nor any of their employees, nor any of their contractors, subcontractors, or their employees, makes any warranty, express or implied, or assumes any legal liability or responsibility for the accuracy, completeness, or usefulness of any information, apparatus, product, or process disclosed, or represents that its use would not infringe privately owned rights. Reference herein to any specific commercial product, process, or service by trade name, trademark, manufacturer, or otherwise, does not necessarily constitute or imply its endorsement, recommendation, or favoring by the United States Government, any agency thereof or any of their contractors or subcontractors. The views and opinions expressed herein do not necessarily state or reflect those of the United States Government, any agency thereof or any of their contractors.

Printed in the United States of America. This report has been reproduced directly from the best available copy.

Available to DOE and DOE contractors from

Office of Scientific and Technical Information

P.O. Box 62

Oak Ridge, TN 37831

Prices available from (615) 576-8401, FTS 626-8401

Available to the public from

National Technical Information Service

U.S. Department of Commerce

5285 Port Royal Rd

Springfield, VA 22161

NTIS price codes

Printed copy: A03

Microfiche copy: A01 
SAND98-0898

Unlimited Release

Printed April 1998
Distribution

Category UC-404, 406, $410,426,704,715$

\title{
A Compact, Repetitive Accelerator for Military and Industrial Applications
}

\author{
F. J. Zutavern, M. W. O'Malley, M. H. Ruebush, L. F Rinehart, \\ G. M. Loubriel, S. R. Babcock, and G. J. Denison. \\ High Power Electromagnetics Dept., Sandia National Laboratories, \\ P.O. Box 5800, Albuquerque, NM 87185-1153
}

\begin{abstract}
A compact, short pulse, repetitive accelerator has many useful military and commercial applications in biological counter-proliferation, materials processing, radiography, and sterilization (medical instruments, waste, and food). The goal of this project was to develop and demonstrate a small, $700 \mathrm{kV}$ accelerator, which can produce $7 \mathrm{kA}$ particle beams with pulse lengths of 10-30 ns at rates up to $50 \mathrm{~Hz}$. At reduced power levels, longer pulses or higher repetition rates (up to $10 \mathrm{kHz}$ ) could be achieved. Two switching technologies were tested: (1) spark gaps, which have been used to build low repetition rate accelerators for many years; and (2) high gain photoconductive semiconductor switches (PCSS), a new solid state switching technology. This plan was economical, because it used existing hardware for the accelerator, and the PCSS material and fabrication for one module was relatively inexpensive. It was research oriented, because it provided a test bed to examine the utility of other emerging switching technologies, such as magnetic switches. At full power, the accelerator will produce $700 \mathrm{kV}$ and $7 \mathrm{kA}$ with either the spark gap or PCSS pulser.

Mature spark gap technology was used to demonstrate operation of the accelerator. Later multiple PCSS were tested with a PFL, which could drive $1 / 8^{\text {th }}$ of the accelerator. The spark gap based system is pulse charged with a low impedance pulse forming line (PFL) which is switched by a single high current spark gap. The PFL drives four small linear induction accelerator (LIA) cavities. In FY95 and 96, the spark gap system was assembled and tested. A field-enhanced diode was tested, and the LIA was analyzed for modifications to operate continuously at $50 \mathrm{~Hz}$. Prolonged testing at $500 \mathrm{kV}$ and $5.5 \mathrm{kA}$ produced several cable breakdown problems, which were repaired, but eventually, the cables will have to be replaced with higher breakdown strength cables for continuous operation. The longest burst tested was 3000 pulses at $30 \mathrm{~Hz}$.

The main advantages of PCSS versus spark gaps for the LIA are lower inductance and greater design flexibility due to the distributed switching that is possible with precisely triggered PCSS. For the LIA and the diode, this translates to faster rise-times, more rectangular pulses, the capability of shorter pulses, and potentially higher diode efficiency. The PCSS-based pulser is composed of 8 identical modules. Each module is switched with six 2-inch diameter PCSS. In FY97, 30 simultaneous current filaments were initiated on a 3-cm wide section of a single switch to limit the current per filament to less than $50 \mathrm{~A}(500 \mathrm{~A} / \mathrm{cm})$ and improve switch lifetime. The first module was assembled and tested to $210 \mathrm{kV}$ and $8 \mathrm{kA}$. Further optimization of the optical trigger delivery system is necessary to reach $250 \mathrm{kV}$ and $10 \mathrm{kA}$ (full power for 1 module) with reasonable PCSS lifetimes ( $>10,000$ pulses). Improved PCSS contacts were developed which demonstrated switch lifetime greater than $10^{7}$ pulses.. However, further resources are necessary to incorporate the new switches, complete the trigger optimization of one module, assemble the other seven identical modules, and test the PCSS-based pulser with the complete LIA.
\end{abstract}




\section{CONTENTS}

0. ABSTRACT

1. INTRODUCTION 1

2. BACKGROUND 2

2.1 Linear Induction Accelerators 2

2.2 Gas Switching Technology 2

2.3 PCSS Technology 3

3. DESIGN

3.1 Compact Linear Induction Accelerator 7

3.2 Gas Switch Pulse Forming System 8

3.3 PCSS-based Pulse Forming System 8

4. ASSEMBLY, TESTING, AND RESULTS 10

4.1 Gas Switch-based Linear Induction Accelerator $\quad 10$

4.2 PCSS Modulator Research and Development $\quad 15$

5. CONCLUSIONS 23 


\section{A Compact, Repetitive Accelerator for Military and Industrial Applications}

\section{INTRODUCTION}

The purpose of this project was to develop and demonstrate a compact linear induction accelerator (LIA) for military and industrial applications. The accelerator operating parameters are: $700 \mathrm{kV}, 7 \mathrm{kA}, 50 \mathrm{~Hz}, 10-30 \mathrm{~ns}$. Two switching technologies were tested: high pressure spark gaps and high gain photoconductive semiconductor switches (PCSS). In FY95, the linear induction cavities from an accelerator designed for a previous project were reclaimed, cleaned, and reassembled as a voltage adder. A spark gap-driven PFL was assembled and tested to drive the 4 cavities in parallel. PCSS lifetime research and experiments were performed to develop an appropriate design for the PCSS-based pulser which would be assembled and tested in the following years. In FY96, the spark gap driven LIA and a field enhanced diode were characterized. Accelerator safety requirements were met and repetitive operation was achieved in bursts. Transformer and cable breakdown problems were analyzed, repaired, and improved repetitive operation was demonstrated. A cooling modification was designed to allow continuous operation of the cavities. The PCSS-based system hardware was assembled and tested in stages. Triggering experiments led us from spot triggering to line triggering for more precise control of the location and number of filaments produced in each PCSS. Various line triggering schemes were tested. In FY97, the accelerator was moved to a new location which will allow eventual testing with the PCSS-based pulser. Approximately 30 filaments were produced with high density line triggering on a single 2-inch diameter PCSS to limit the current per filament to less than $50 \mathrm{~A}(500 \mathrm{~A} / \mathrm{cm})$. One of 8 modules of the PCSS pulser was assembled and tested with six 2-inch PCSS. This module was tested to $210 \mathrm{kV}$ and approximately $8 \mathrm{kA}$. Design goals for the pulser were $250 \mathrm{kV}$ and $10 \mathrm{kA}$, which would exceed the requirements of the LIA cavities for the accelerator. As it became clear that the assembly and testing of all 8 modules for the PCSS-based pulser was not going to be possible under the time and funding constraints for this project, our emphasis turned to learning as much as we could about multiple filament PCSS triggering and the operation of the 6-switch module.

In the future, this accelerator can continue to serve as a test bed for spark gap, PCSS, and other emerging switching technologies, such as advanced magnetic switches and other high speed solid state switches. In addition, it can be used to develop high average power particle beam diodes. Higher breakdown strength cables may be required to reach the full operating parameters of the accelerator for extended periods of operation. To complete the PCSS pulser, approximately one more year of developmental testing and assembly is required. Our present plan would be to use our high speed, extended IR sensitive, intensified camera through a long operating distance microscope for precise alignment and optimization of the line-triggered filaments on each switch. A better method of optical trigger pulse delivery and cylindrical lens positioning is probably required in order to achieve optimum results on all 48 PCSS in the complete pulser. Improvements in switch mounting/packaging technology are also required to avoid damage from the shock wave caused by occasional electrical breakdowns elsewhere in the pulse forming system. 


\section{BACKGROUND}

2.1 Linear Induction Accelerators (LIA). Magnetic induction has been used for linear electron accelerators such as ETA and ATA at LLNL ${ }^{1}$. At SNL the concept has been applied to voltage-adders for both electron and ion beam accelerators ${ }^{2 \cdot 3 \cdot 4}$. The advantage to a LIA, which makes it useful for compact applications, is that it is constructed from a series of identical cavities and the voltage from each cavity adds to the accelerating voltage of the whole accelerator. The cavities are inductively isolated from each other for short pulses, so a pulse modulator can deliver a few hundred kilovolts in parallel to all the cavities. The total accelerating voltage, which is as high as $20 \mathrm{MV}$ for Hermes III at SNL, is the sum of the voltages from all of the cavities in series. This eliminates the need to handle extremely high voltages for time periods longer than the accelerating pulse (10$30 \mathrm{~ns}$ for this project). A disadvantage of a LIA, is that the time isolation is obtained from feromagnetic material which has high density. The relation between voltage standoff, $V$ and the time period, $\Delta t$, is approximately given by:

$$
V=\frac{\Delta B_{\text {sat }} A}{\Delta t}
$$

where $A$ is the cross-sectional area of the ferro-magnetic "donut" which surronds the accelerating beam, and $\Delta B_{\text {sat }}$ is the maximum magnetic field change which can be achieved in the ferromagnetic material during short pulses. To minimize the size and weight of this type of accelerator, the design must minimize the radius of the ferromagnetic "donut." Fortunately, for this project, an existing LIA was available which had been designed for another project with similar goals for size, volume, and operating parameters. This accelerator is described briefly in the design section (3.1 LIA) of this document.

2.2 Gas Switching Technology. High voltage gas breakdown switches, commonly called spark gaps, are used frequently in conventional pulse power technology. They can be designed to operate from a few kilovolts to over $1 \mathrm{MV}$, and can conduct hundreds of kA. For this application only one switch is required, so switch jitter is not an issue. Repetition rate (lifetime) and inductance are the main issues. The stability of high pressure spark gaps operating at current levels, which are required for this project has been carefully studied ${ }^{5}$. A light-weight, high-energy modulator with similar design requirements has been built using this type of spark gap technology for $200 \mathrm{kV}$

${ }^{1}$ L. Reginato, IEEE Trans. Nucl. Science, NS-30, Aug., 1983, p. 2970.

2 J.J. Ramirez et. al., "The Four Stage HELIA Experiment", Proc. $5^{\text {th }}$ IEEE Pulsed Power Conf., Arlington, VA (1985).

3 J. J. Ramirez, "Very High Pulse Energy Accelerators, Particle Accelerator Conference, Chicago, IL, March 20-23, 1989.

4 J. A. Alexander, J. P. Corley, D. L. Johnson, G. J. Denison, K. Hodge, P. Pankuch, J. J. Ramirez, "Performance of the Hermes III Pulse Forming Lines," Proc. 7th IEEE Pulsed Power Conference, Monterey, CA, June, 1989.

${ }^{5}$ L. F. Rinehart and M. T. Buttram, "Statistical Distributions of Breakdown Voltages in a High Current Spark Gap," Proc. of $17^{\text {th }}$ IEEE Power Modulator Symposium, Seattle, WA, June, 1986, pp[ 138-145. 
applications with 1-2.5 Ohm loads 6 . This project requires a spark gap that stands-off 500 $\mathrm{kV}$ and drives a $6.25 \mathrm{Ohm}$ load, so a similar, but longer gap, switch was designed and tested. The modulator which was designed around this switch is described in the design section (3.2 Gas Switch Pulse Forming System).

2.3 PCSS Technology. High gain PCSS offer switching improvements over conventional high voltage switching technologies in voltage, current, rise time, jitter, optical activation, size, and cost. High voltage operation of conventional (linear) PCSS, is limited by optical trigger energy requirements, which are 1,000 to 100,000 times greater than those for high gain PCSS. To understand and develop high gain PCSS many experiments have been performed ${ }^{7}$. The following paragraphs provide a brief description of some of these associated properties and issues: (1) high gain, (2) current filaments, (3) device longevity, and (4) switching characteristics.

2.3.1. High Gain: Conventional PCSS produce only 1 electron-hole pair per absorbed photon. The energy of the individual photons excite electrons from the valence band to the conduction band. This excitation is independent of the electric field across the switch, and conventional PCSS can be operated to arbitrarily low voltage. High gain PCSS, on the other hand, occurs only at high electric fields (greater than $4 \mathrm{kV} / \mathrm{cm}$ ). The photo-excited carriers, which are produced by an optical trigger, gain enough energy from the electric field to scatter valence electrons into the conduction band. This process is called impact ionization or avalanche carrier generation. Because many carriers are produced per absorbed photon, switches operating in this mode require extremely low energy optical trigger pulses, and they are called high gain PCSS in contrast to the conventional PCSS, which are often called linear PCSS. To stand off high voltage, PCSS must be made long enough to avoid avalanche carrier generation with no optical trigger (dark breakdown). The optical trigger energy for a linear PCSS scales with the square of its length. So high voltage linear PCSS can require rather high energy optical trigger pulses ( $25 \mathrm{~mJ}$ for $100 \mathrm{kV}$ switches switched to $1 \Omega$ ). It is the high gain feature of GaAs

${ }^{6}$ L. F. Rinehart, R. S. Clark, M. T. Buttram, J. E. Mikkalson, P. E. Patterson, "A Repetitive, 1 Microsecond, $35 \mathrm{~kJ}, 200 \mathrm{kV}$ Pulse Generator," Proc. of $19^{\text {th }}$ IEEE Power Modulator Symposium, San Diego, CA, June, 1990, pp. 448-453.

${ }^{7}$ For references on high gain PCSS technology see the following:

a.) IEEE Pulsed Power Conferences, 1985-97 (odd years)

b.) IEEE Power Modulator Symposia, 1986-96 (even years)

c.) SPIE Optically Activated Switching Conferences I-IV, 1990, 1992, 1993, 1994.

d.) F. J. Zutavern, G. M. Loubriel, M. W. O'Malley, L. P. Schanwald, W. D. Helgeson, D. L. McLaughlin, and B. B. McKenzie, "Photoconductive semiconductor switch experiments for pulsed power applications," IEEE Trans. Elect. Devices, 37, No. 12, 1990, pp. 2472-2477.

e.) A. Rosen and F. J. Zutavern, Eds., High-Power Optically Activated Solid State Switches, Artech House, Boston, 1993, pp. 245-296.

f.) G. M. Loubriel, F. J. Zutavern, H. P. Hjalmarson, R. R. Gallegos, W. D. Helgeson, and M. W. O'Malley, "Measurement of the Velocity of Current Filaments in Optically Triggered, High Gain GaAs Switches", Applied Physics Letters, 64, No. 24, 13 June, 1994, pp. 3323-3325.

g.) G. M. Loubriel, F. J. Zutavern, A. G. Baca, H. P. Hjalmarson, T. A. Plut, W. D. Helgeson, M. W. O'Malley, M. H. Ruebush, and D. J. Brown, "Photoconductive Semiconductor Switches," IEEE Transactions on Plasma Science, 25, 1997, pp. 124-130. 
PCSS that allows their triggering with small semiconductor LDA. We have triggered 100 $\mathrm{kV}$ gallium arsenide (GaAs) PCSS, with as little as $90 \mathrm{~nJ}$. A GaAs PCSS, operating in a low impedance circuit, can produce 100,000 times as many carriers as a linear PCSS would produce.

With most insulating materials (e.g. plastic, ceramic, or glass) and undoped semiconductors (e.g. silicon, gallium phosphide (GaP), or diamond), bulk avalanche carrier generation does not occur below $200 \mathrm{kV} / \mathrm{cm}$. Semiconductors such as GaAs and indium phosphide (InP) are very different in that high gain PCSS can be initiated at unusually low electric fields (4-6 kV/cm and $15 \mathrm{kV} / \mathrm{cm}$, resp.). Surface breakdown limits the field across PCSS to less than the bulk breakdown field (generally $100 \mathrm{kV} / \mathrm{cm}$ ). Since PCSS need to absorb light through a surface, optically-activated avalanche breakdown is only practical in materials which exhibit high gain at lower fields. A very important part of the research into high gain PCSS has been to develop models for high gain at low fields in these materials.

Once avalanche carrier generation is initiated, it continues until the field across the switch drops below a threshold (4-6 kV/cm depending upon the type of GaAs). Since carrier generation causes the switch resistance to drop, in most circuits the field across the switch will also drop. Indeed, when we first observed high gain PCSS, the most outstanding feature was that at high fields, when the switches would turn on, their voltage
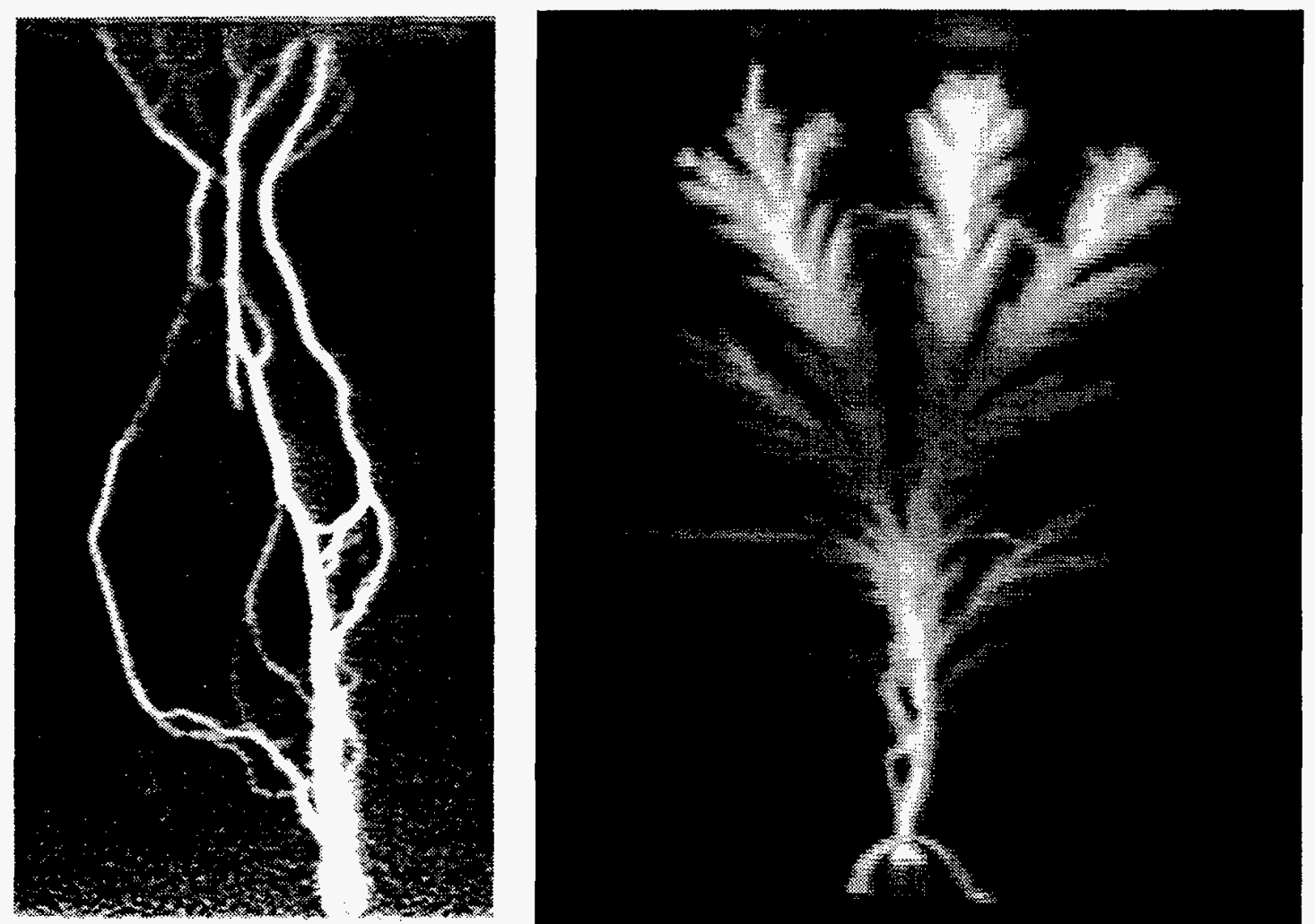

Figure 2.1. These photographs show examples of the current filaments which form during high gain PCSS operation. The images are recorded from the infrared $(875 \mathrm{~nm})$ radiation which is emitted as the carriers recombine in the switch. In both cases, the switches are $1.5 \mathrm{~cm}$ long (vertically). The PCSS on the left was charged to $45 \mathrm{kV}$ and conducted $350 \mathrm{~A}$ for $10 \mathrm{~ns}$. The PCSS on the right was charged to $100 \mathrm{kV}$ and conducted $900 \mathrm{~A}$ for $1.4 \mathrm{~ns}$. 
would drop to a constant non-zero value and stay there until the energy in the test circuit was dissipated. We originally called this switching mode "lock-on" to describe this effect. "High gain" has been adopted more recently to help distinguish this type of switching mode from other modes which also exhibit persistent conductivity, such as thermal runaway, and single or double injection. The field dependence for avalanche carrier generation that is exhibited in high gain PCSS is similar to that exhibited by Zener diodes. In series with a current limiting resistor, they will conduct whatever current is necessary to maintain a constant voltage across their contacts. In the case of a high gain PCSS, this voltage/field is the "lock-on" voltage/field or the threshold to low field avalanche carrier generation. The phase of switching during which the switch maintains this constant voltage drop is called the sustaining phase, and testing and modeling this phase is also a critical area of our research.

2.3.2. Current Filaments: Another important feature of high gain PCSS is that the current forms in filaments which are easily observed with a near infra-red sensitive camera (most non-intensified, black and white, CCD-based cameras). When the carriers recombine (i.e. conduction electrons drop back into the valence band), infra-red photons are emitted at approximately $875 \mathrm{~nm}(1.4 \mathrm{eV})$. If the filaments are near the surface of the switch, the emitted photons escape and they can be detected by a camera. Some images obtained in this manner are shown in figure 2.1. We believe that current filaments are fundamental to high gain PCSS and we have never observed high gain without current filaments. While current filamentation can lead to catastrophic destruction of the PCSS, current amplitude and pulse widths can be limited to allow non-destructive operation. In addition, the optical trigger can be distributed across the switch in a manner which creates multiple or diffuse filaments to extend the lifetime or current carrying capacity of the switch. Figure 2.2 shows the image of a switch which was illuminated with 30 parallel lines of light to produce multiple filaments. The length of the filaments $3.4 \mathrm{~cm}$ and the distance between them was approximately $1 \mathrm{~mm}$.

2.3.3. Device Longevity: The biggest problem caused by the filaments is the gradual accumulation of damage at the contacts which limits their useful life to $1-10,000,000$ shots depending upon the current per filament and the optical trigger distribution. Presently, device lifetime is a limitation of this technology for many applications. Although there is little change in performance, the PCSS degrade in time because the regions near the contacts are damaged on each pulse, and they gradually erode. The bulk

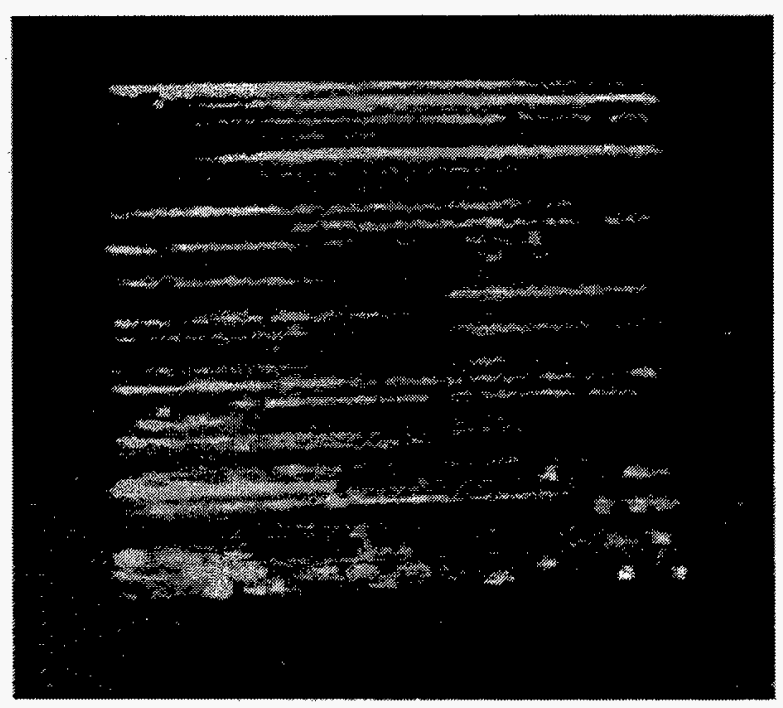

Figure 2.2 This switch was illuminated with 30 parallel lines of light to initiate current filaments which are $3.4 \mathrm{~cm}$ long and separated by only 1 $\mathrm{mm}$. The filaments are triggered and viewed through a layer of $1 \mathrm{~mm}$ diameter glass rods which are submersed in Fluorinert and $1 \mathrm{~mm}$ above the GaAs wafer. Total current is $380 \mathrm{~A}$ (13A/filament). 
semiconducting material shows very little, if any, degradation as the contact regions wear out. The fact that the degradation is confined to regions near the contacts suggests that substantial increases in switch lifetime can be made by developing better contacts that allow for higher current density. When this project started, high-gain PCSS would last for $\sim 10^{4}$ pulses under a specific set of test conditions ( $0.5 \mathrm{MW})$. During the course of this project, the lifetime has been improved to $2.4 \times 10^{7}$. In comparison, the semiconductor lasers, which trigger or are driven by these switches, can last from $10^{8}$ to $10^{10}$ pulses. We are presently fabricating new generations of deep-diffused and epitaxial-grown contacts that should yield further improvements. At higher powers or longer pulses, lifetimes are reduced. We plan to address these issues and accelerate lifetime testing by shifting our interests to higher current and higher repetition rate testing. We expect to improve lifetimes by another two orders of magnitude in the next two years.

2.3.4. Switching Characteristics: A summary of switching characteristics is given in table 2.1. The values in this table continue to be updated as we develop and test better contacts, configurations, and circuits. Since this is a relatively new technology, there is much to discover about switch operation. Initiation of the current filaments, the filament carrier density and size, current crowding and energy deposition at the contacts, and interaction between the high gain PCSS and other circuit components are all critical areas of research and development. Continued experimental and theoretical solid-state device research will develop and verify operational and fundamental models for the behavior of these switches over a wide range of parameter space. These models will allow accurate predictions of the strengths and weaknesses of this technology and improve our ability to design switches for specific applications. 


\section{DESIGN}

3.1 Compact Linear Induction Accelerator (LIA). The LIA cavities used in this project were originally designed and developed for the DELPHI program, which was a project that required a relatively light weight, compact accelerator ${ }^{1}$. This experimental accelerator consisted of four LIA cavities designed to deliver $250 \mathrm{kV}$ across a $10 \mathrm{kA}$ beam ( $25 \mathrm{Ohm}$ load). The cylindrical cavities are fed in parallel with two, high voltage, $50 \mathrm{Ohm}$, coaxial cables which entered the cavities radially separated by an angle of 180 degrees around the accelerating axis. Stacked ferrite cores produced enough inductance to hold the $250 \mathrm{kV}$ output voltage for at least $30 \mathrm{~ns}$. When stacked in series, the four accelerating cavities ideally made a $100 \mathrm{Ohm}$ accelerator which delivered $1 \mathrm{MV}$ across 10 $\mathrm{kA}$. In previous tests, the four cavities used for this project were used in conjunction with two post-accelerating cavities to produce a ringing waveform with peak output parameters of $1.3 \mathrm{MV}$ and $1.2 \mathrm{kA}^{2}$. Figure 3.1 shows a cross-sectional view of the LIA cavities and their ferrite cores. For our tests, a field enhanced cathode, consisting of a ring of 5 needles, and a brass, water-cooled cathode plate was used to form the diode.

Cavity feed voltages were monitored with capacitive voltage monitors, which sensed the time derivative of the voltage delivered to each cavity. Beam current was monitored with a calibrated Rogowski coil near the anode. The system was evacuated to $2 \times 10^{-5}$ Torr. The modulator required to drive the LIAs must supply $250 \mathrm{kV}$ to eight $50 \mathrm{Ohm}$ cables, i.e. a total $40 \mathrm{kA}$ or a 6.25 $\mathrm{Ohm}$ load. With an ideal beam $(10 \mathrm{kA})$ the impedance of the accelerating cavities matches the cables. However, as the beam turns on, the cavity impedance is very high and the initial voltage edge is reflected back to the modulator, which must be protected from these "voltage doubling spikes". Pictures of these components are shown in secion 4.1.

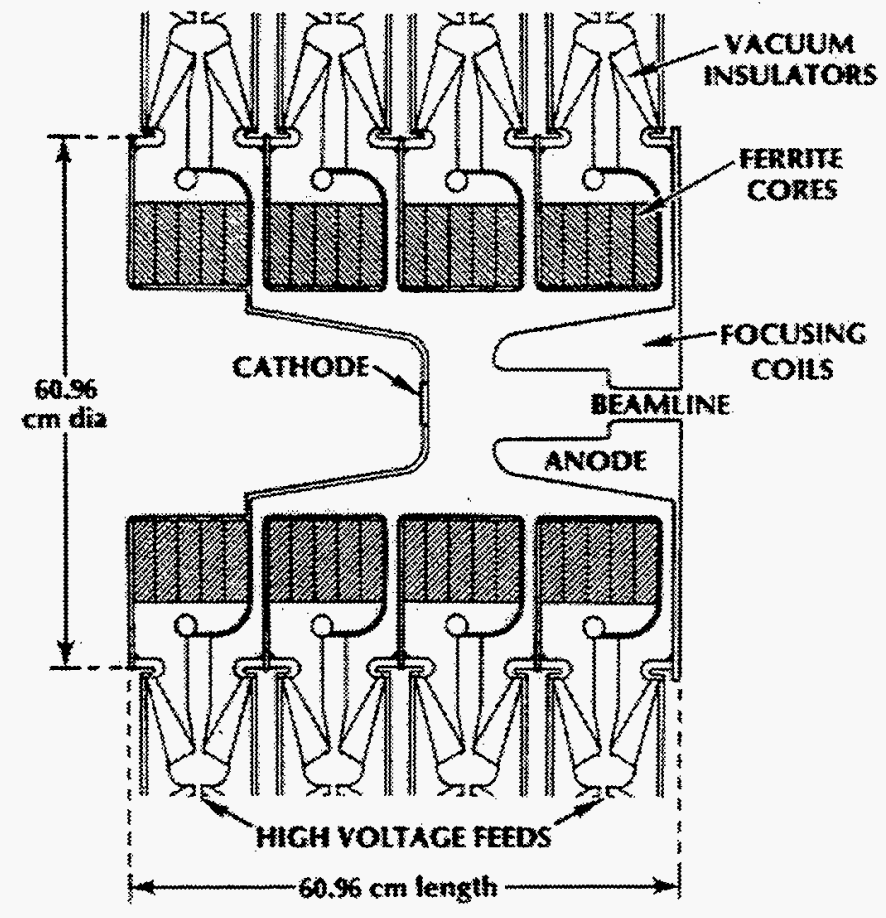

Figure 3.1. This cross-section of the LIA shows the ferrite cores and the compact configuration which is achieved using inductive isolation. The anode was replaced with a solid, field enhanced version.

${ }^{1}$ K. T. Lancaster, R. W. Stinnett, M. T. Buttram, R. S. Clark, J. W. Ginn, J. W. Poukey, "The PT0 Linear Induction Accelerator," Proc. of $6^{\text {th }}$ IEEE Pulsed Power Conference, Arlington, VA, June, 1987, pp 374377.

2 J. M. Wilson, L. L. Torrison, J. W. Poukey, R. J. Adler, S. Humphries, Jr., "The Compact Linear Accelerator Program at Sandia National Laboratories," Proc. of the $19^{\text {th }}$ IEEE Power Modulator Symposium, San Diego, CA, June, 1990, pp 114-118. 
3.2 Gas Switch Pulse Forming System. The high voltage modulator consists of a 30 ns, $6.25 \mathrm{Ohm}$ pulse forming line (PFL). The PFL uses water as the insulating dielectric for its high relative dielectric constant (78) and reasonable breakdown strength with short pulses. With this dielectric constant, a coaxial transmission line of fixed outer diameter has the minimum (optimum) field on its inner conductor when its impedance is 7 Ohms. This large dielectric constant also implies that a $30 \mathrm{~ns}$ long pulse can be formed from a charged section of line that is only $\sim 20$ inches long. The water line is charged by a thyratron-driven pulse transformer in approximately 2 microseconds. Since the voltage delivered to the output of the PFL is half the charge voltage, the pulse transformer must charge the line to $500 \mathrm{kV}$. A Blumlein configuration could have reduced the charge voltage requirement to $250 \mathrm{kV}$, but the spark gap inductance would probably have been too large to deliver the required 5-10 ns rise time. (Rise time, in this case, is proportional to $L / R$ where $L$ is the switch inductance and $R$ is the impedance of the transmission line. The Blumlein impedance would be $3.12 \mathrm{Ohm}$, half the impedance of the present PFL.) A thyratron-switched modulator stores up to 360 joules per pulse and has been operated up to $50 \mathrm{~Hz}$ at that energy ( $18 \mathrm{~kW}$ average power). The thyratron switches the energy from DC charged capacitors through a pulse transformer which charges the pulse forming line (PFL) to $500 \mathrm{kV}$. The PFL is switched with a high pressure gas spark gap and delivers $250 \mathrm{kV}$ to the eight $50 \mathrm{ohm}$ coaxial cables, which drive the four LIA cavities. Pictures of the assembled modulator are shown in section 4.1.

3.3 PCSS-based Pulse Forming System. After extensive PCSS testing, the design for the PCSS pulser was completed early in FY96. This system consists of eight, water-filled Blumleins that each supply $250 \mathrm{kV} 30 \mathrm{~ns}$ pulses to a single high voltage $50 \mathrm{Ohm}$ cable. The low impedance Blumlein configuration could be used with the PCSS because the inductance of many PCSS switches is much less than the single spark gap switch described above. All together, the eight parallel plate Blumleins form a nearly cylindrical (octagonal) system of concentric lines to eliminate stray fields and current flow around their edges which are the most significant source of inefficiency in a Blumlein. The eight Blumleins will be switched simultaneously by 48,2 " diameter, GaAs PCSS.

The octagonal configuration allows for easier switch trigger configuration because the switches in a single module are collinear. It also produces a more uniform electric field across the insulating region of each PCSS than a circular configuration would produce. One unusual property of the modules is that when they are tested separately, their stray fields will cause a significant reduction in their impedance, which should be 50 Ohms to match the cable impedance. This means that there will be some significant reflection of the pulse at the Blumlein to cable interface when the modules are operated individually. When operated together, they should be matched to the transmission lines, because their are no stray fields near their edges. The eight cables from the Blumleins will drive the four linear induction cavities. The end view of these Blumleins is shown in figure 3.2. Water was used as the dielectric storage medium to minimize the volume of the Blumleins. As with the spark gap PFL, a $30 \mathrm{~ns}$ pulse can be obtained from a water line that is only 20 inches long, whereas an oil line would have to be $10 \mathrm{ft}$. long. To maximize the lifetime of the PCSS switch, the current per filament was limited to $50 \mathrm{~A}$. 
To switch a total current of $80 \mathrm{kA}, 1600$ current filaments must be initiated on the 48 switches (33 filaments per switch). Multiple filaments had been demonstrated at lower voltages and with fewer switches, but this was the crucial development area for this technology.

Initially, filaments were to be triggered with two optical fibers per filament, one at each end near the contacts. Sixteen fiber optic bundles would be used to divide a single $50 \mathrm{~mJ}, 6 \mathrm{~ns}$ optical pulse at $532 \mathrm{~nm}$ into 3200 fibers, each $200 \mu \mathrm{m}$ in diameter. The fibers were arranged in a row along each contact. Trigger testing eventually showed that line triggers (a continuous line of light) which extended across the entire insulating gap of the PCSS produced the most densely packed arrangement of filaments. (See figure 2.) Although the energy requirement was somewhat larger for line triggers (1-10 microjoules per filament), the total energy requirement was still less than $30 \mathrm{~mJ}$. In this modified trigger scheme, light was still delivered to the switch assembly in the fiber bundles, but after exiting the fibers it was focused into lines with 1 $\mathrm{mm}$ diameter glass rods which were held parallel to the switch surfaces in the direction of current flow.

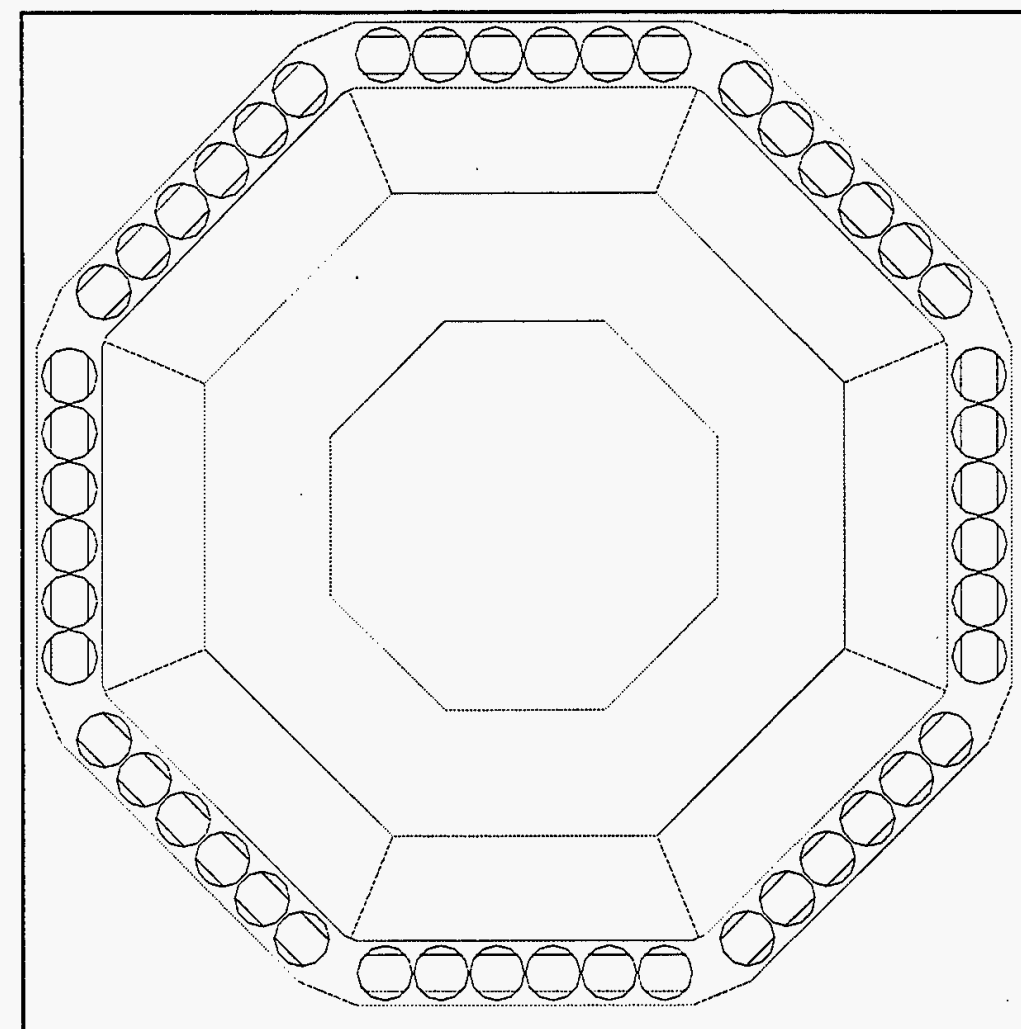

Fig. 3.2 The end (top) view of 8 water-filled parallel-plate Blumleins shows how they form a single octagonal Blumlein. $48 \mathrm{GaAs}$ wafers (circles) switch this end of the Blumlein and deliver a $30 \mathrm{~ns}$ long, $250 \mathrm{kV}$ pulse to eight 50 $\mathrm{Ohm}$, coaxial cable, transmission lines. The cables charge 4 LIA cavities and the sum of their voltages produces the accelerating voltage with $70-80 \%$ efficiency $(700-800 \mathrm{kV})$. The outer dimension is approximately $3 \mathrm{ft}$. The center and outer octagons are the ends of the inner and outer conductor of the Blumlein. The trapezoids are metal surfaces which connect the switches to the middle conductor of the Blumlein. This configuration allows a higher field near the middle conductor than could be withstood by the PCSS surfaces. 


\section{ASEMBLY, TESTING, AND RESULTS}

4.1 Gas Switch-based Linear Induction Accelerator. Two events in the initial stages of this LDRD led us to consider alternative accelerator designs. The first was a meeting on September 20, 1994 with the local pulsed power technology transfer experts to discuss "market needs" for a compact industrial accelerator. The second was the recovery of the linear induction accelerator (LIA), called PT0, from the former Delphi program. Relatively minor changes in the original goals of the program were proposed to take advantage of the LIA and to better meet perceived market requirements. However, these changes were significant in detail, and are discussed below.

The "market needs" meeting made it clear that longer pulses would be advantageous for several industrial applications and also reduce some of the technical risks in the diode. Limitations in our prime power require a tradeoff in current to accommodate longer pulses, but this tradeoff appears to be our best approach. We would increase our pulse length goal from $7 \mathrm{~ns}$ to $30 \mathrm{~ns}$ (testing down to $10 \mathrm{~ns}$ ), but reduce our total current from $14 \mathrm{kA}$ to $7 \mathrm{kA}$. This change would double the total energy per pulse.

The recovery of the Delphi LIA meant that a superior accelerator was within the scope of our LDRD funding. A LIA was not considered in our original proposal, because a new LIA (particularly its ferrite cores) represents a substantial program cost for design and fabrication $(\sim 1 M)$. However, modifications to this existing system could produce an accelerator which would exceed our original goals and increase our chances of success. The LIA basically allowed us to produce an efficient accelerator by building four modules which operate at one fourth of the total accelerator voltage. The challenge of our modified proposal was to drive the compact Delphi LIA at a $50 \mathrm{~Hz}$

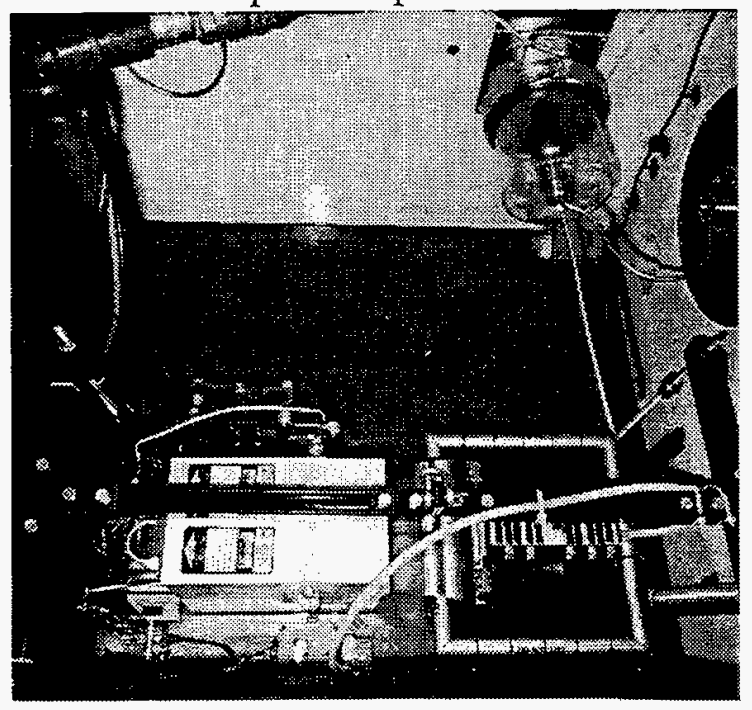

Figure 4.1. The inside of the oil tank (normally full) shows (left to right) the thyratron, capacitors, pulse transformer, and oil-water interface (upper right).

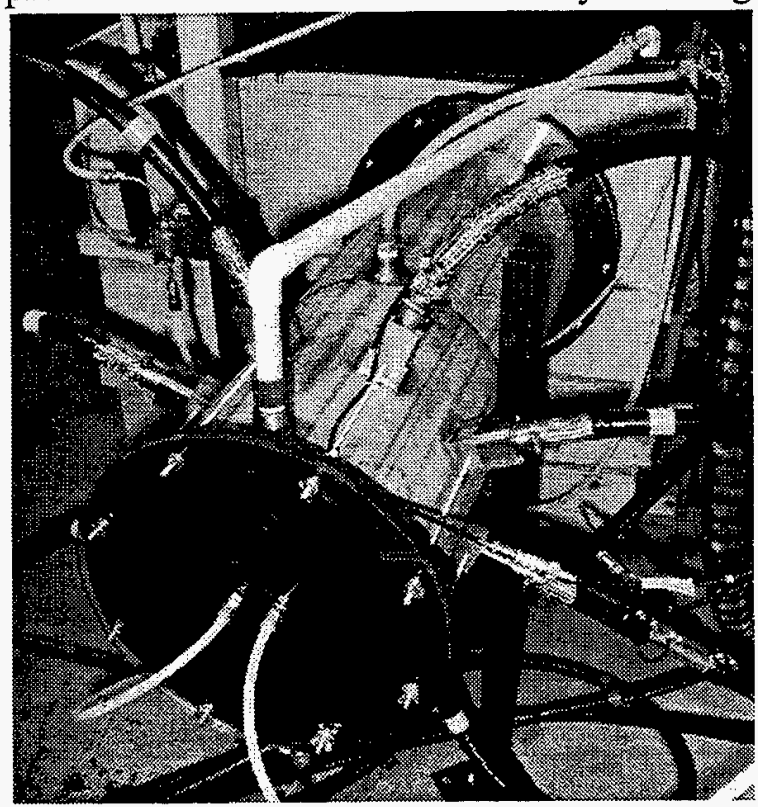

Figure 4.2. The $25 \mathrm{~cm}$ dia., $6.2 \mathrm{Ohm}$, waterfilled, pulse forming line (PFL)is attached to the outside of the oil tank at an oil-water interface. When the spark gap inside the PFL is triggered a $30 \mathrm{~ns}$ long pulse is transmitted into 8 coaxial, $50 \mathrm{Ohm}$ cables. 
repetition rate using conventional spark gap technology and high gain GaAs PCSS. This configuration was considered to be valuable in meeting perceived market needs for repetitive pulsed power technology.

The storage capacitors, thyratron, pulse transformer, and oilwater interface for the modulator were assembled in a $4 \mathrm{X} 4 \mathrm{X} 4 \mathrm{ft}^{3}$ oil tank and are shown in figure 4.1. A 30-inch long X 10-inch diameter stainless steel, 6.25 Ohm, coaxial transmission line was assembled and mounted on the side of the tank to an oil-water interface. Eight cable feed-thrus were welded radially around the output end of the pulse forming line (PFL). The outside of the oil tank, the PFL, and the cables are shown in figure 4.2. The modulator,

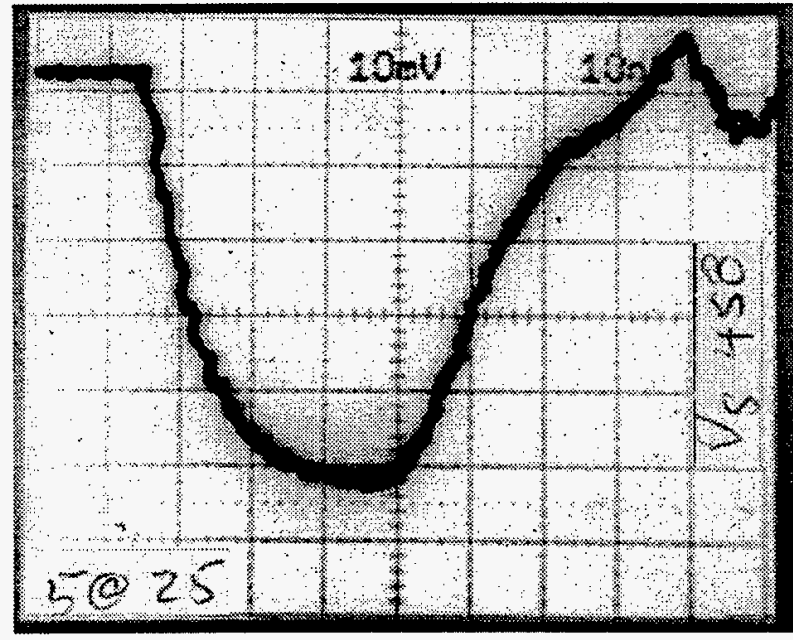

Figure 4.3. Five overlaid voltage waveforms shown here were produced by the spark-gap driven PFL (6.25 $\Omega$ ). The rep-rate was $25 \mathrm{~Hz}$, charge voltage was $460 \mathrm{kV}$, and peak output voltage approximately $220 \mathrm{kV}$. The output voltage for an ideal switch would be $230 \mathrm{kV}$. The PFL will drive 4 LIA cavities. Time units are $10 \mathrm{~ns} /$ division.

\section{$\mathrm{PFL}$, and cables terminated with 50}

Ohm loads, were tested to $485 \mathrm{kV}$ charging voltage, at $25 \mathrm{~Hz}$. During this testing, the water-oil interface broke down. The problem was analyzed and believed to be cause by insufficient oil flow near the interface for this repetition rate. The interface was repaired, oil flow was increased and tests were resumed up to $460 \mathrm{kV}$. The output from one of the cables when the modulator was charged to $460 \mathrm{kV}$ is shown in figure 4.3. At this level, $90 \%$ efficient voltage addition in the LIAs would produce $800 \mathrm{kV}$, which would exceed our goals for the LIA.

The accelerator
cavities which were
assembled for a previous
project were actually
"rescued" as they were
leaving the area IV gate on the way to reclamation. Although they represented a significant savings in design, materials, and fabrication, they had been stored outside and required considerable cleaning and refurbishing before they could be reassembled and vacuum tested. When the

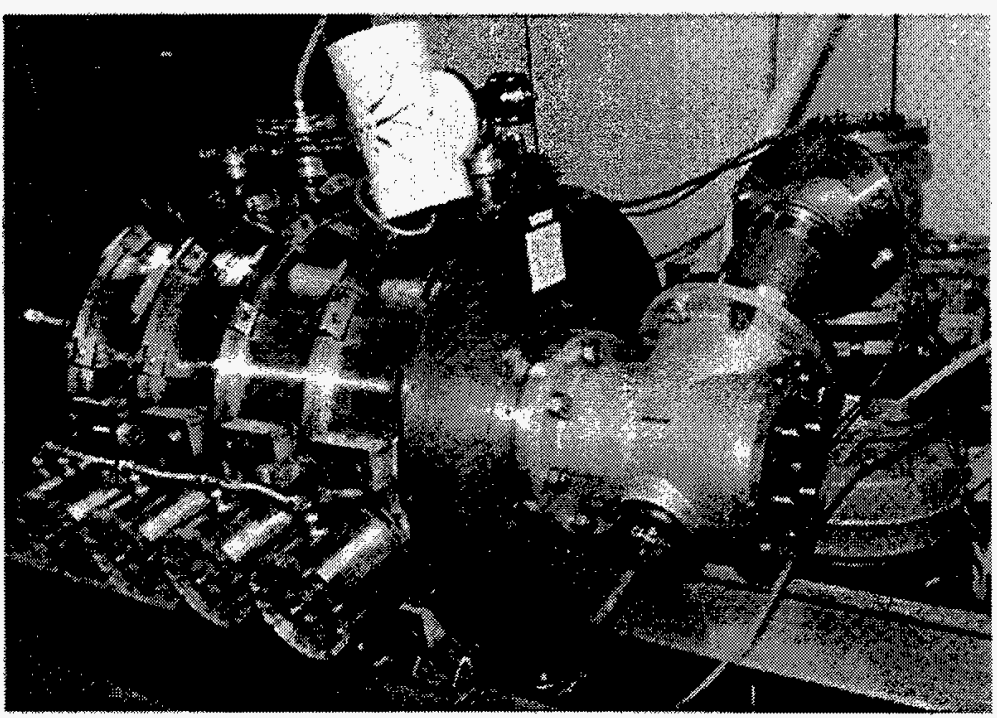

Figure 4.4. The four 24-inch diameter LLA cavities are shown here after cleaning and replacing all weathered parts. 
vacuum system pressure reached $2 \times 10^{-5}$ Torr, it was considered satisfactory for accelerator operation. A picture of the refurbished accelerator cavities is shown in figure 4.4. To avoid producing ionizing radiation, initial testing of the cavities was done as a voltage adder across a $100 \mathrm{Ohm}$ water resistor. The water resistor was insulated with $\mathrm{SF}_{6}$ and was limited in voltage to $650 \mathrm{kV}$. Waveforms from these tests implied that when the modulator was charged to $485 \mathrm{kV}$, the cavities would produce $720 \mathrm{kV}$, which would exceed our goal for the accelerator of $700 \mathrm{kV}$. The open accelerator, the water resistor used for testing, and one of the original cathodes for the accelerator are shown in figure 4.5 .

The next task for the spark-gap based accelerator was to build a radiation cell and satisfy radiation safety requirements. After the expected radiation

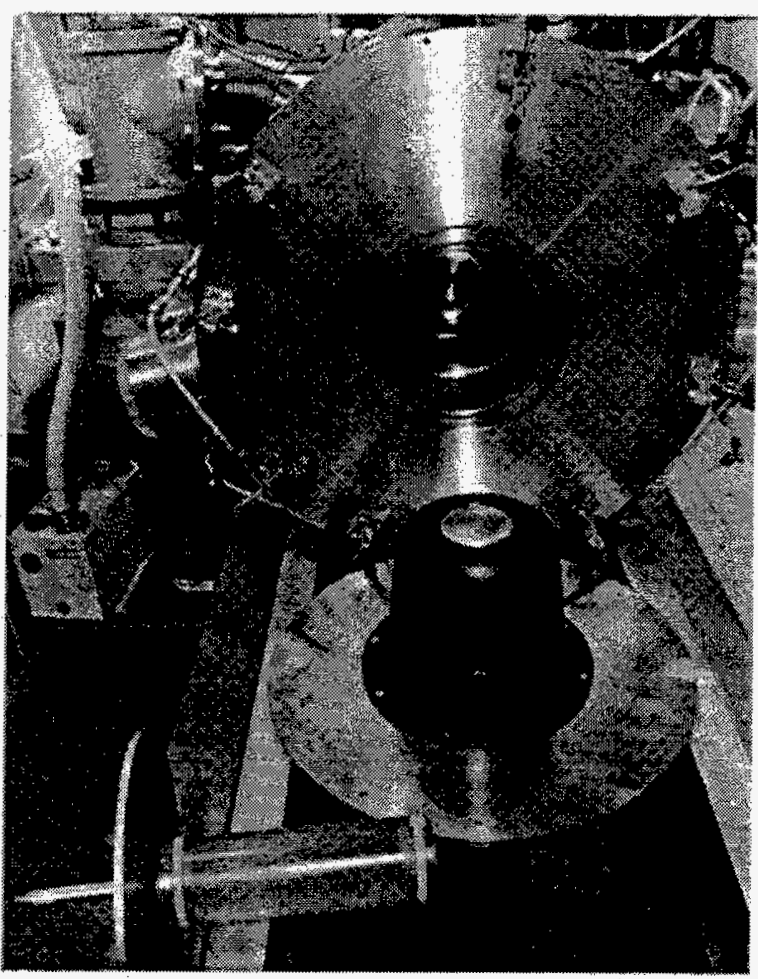

Figure 4.5. The LIA is shown from the anode end, with the water resistor, and one of the original cathodes.

was calculated, shielding was positioned around the machine, an SOP and OP were written and approved by SNL safety and the pulse power safety committee. Single shot testing was initiated and dosimetry was monitored to verify the calculations. Initially a single tip, field enhanced diode was used to generate the beam. Since the current generated with this diode was low, a five tip arrangement was installed. The highest voltage and current tested initially was $480 \mathrm{kV}$ and $5.5 \mathrm{kA}(90 \Omega)$ at $2 / 3$ the full charge voltage. The waveforms measured at this charge voltage are shown in figures 4.6 and 4.7. As we continued to increase the power, the impedance of the diode would drop, so

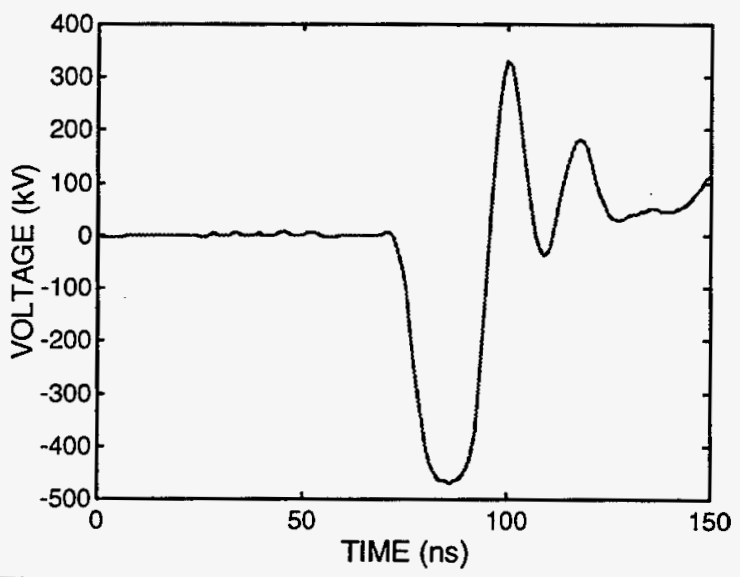

Figure 4.6. The diode voltage measured at $2 / 3$ full pulse charge rating.

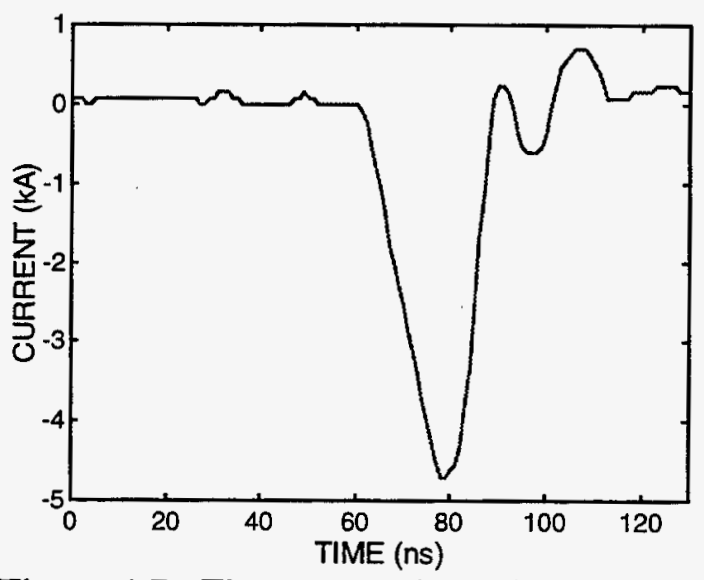

Figure 4.7. The current through the diode at $2 / 3$ full pulse charge rating. 
some of the tips must be removed to maintain the approximate $100 \mathrm{Ohm}$ impedance. After several weeks of single shot operation, approval was granted to operate the machine at full power ( $7 \mathrm{GW}$ ) and repetition rate $(50 \mathrm{~Hz})$. We continued to monitor the dosimetry as we gradually increased the power and/or the repetition rate to reach the full design specifications.

During prolonged repetitive testing at $2 / 3$ full charge to measure cavity heating, the secondary winding on the charging transformer tracked along an insulating brace. The transformer is submerged in oil and had been previously tested at $50 \mathrm{~Hz}$ and full voltage. Since the break-down was along an interface of the brace, it is likely that it was induced by trapped air. The transformer was repaired with larger diameter wire (to reduce the electric field) and thicker insulation. To eliminate trapped air, it was vacuum pumped under oil. Some resistance was added to the coupling between the transformer and the PFL to damp the transient voltage spikes without reducing the voltage to the PFL significantly.

New, extended-memory, data acquisition instrumentation was installed that allowed continuous monitoring of every pulse for a burst of up to 1000 pulses. Upon inspection of the data from the cavity V-dot monitors, it was observed that there was a significance difference between even and odd number pulses. One group of pulses would show proper operation of the accelerator, and the other showed an apparent problem with voltage hold-off in at the cavities. It was suggested that the ferrite cores were not always returning to the same initial position on their hysteresis loop. A good pulse was always followed by a bad pulse which showed high frequency ringing and probably reset the ferrite cores so that the next pulse would be another good one. The original accelerator was designed to supply a ringing waveform to a mis-matched load, so a reset circuit had not been required. For our application, a DC reset circuit was designed, which used a high current automotive battery charger for the power supply. It was coupled to the accelerator and run continuously when the pulse modulator was being tested. Not only did this solve the problem of even-odd waveform variation, it actually produced a better (more flat-topped) pulse at the accelerating cavities. This is an indication that a greater $\Delta B$ is achieved with the reset pulse than had been achieved before on every 2 nd pulse. The improved cavity and beam pulse shapes are shown in figure 4.8.

Before continuous operation could be achieved, cooling modifications have to be made to the anode, which dissipate the beam energy, and energy lost in the magnetic 
cores of the LIA cavities. Based upon the voltage and current waveforms, the cavities are approximately $70 \%$ efficient. Estimates of the power dissipated were made and showed that this thermal energy could be removed with a modest amount of chilled water circulation. It was estimated that at full power and $50 \mathrm{~Hz}$ repetition rate, the anode will dissipate $7.5 \mathrm{~kW}$ and the cores $2.5 \mathrm{~kW}$. This can be removed from the anode with 2.2 $1 / \mathrm{min}$. and from the cores with $0.75 \mathrm{l} / \mathrm{min}$. of chilled water with a $50 \mathrm{C}$ temperature change. Without cooling, a rise of $1 \mathrm{C}$ should occur at the anode after 10 shots and at the cores after 4200 shots, because the cores have much more mass than the anode.

To measure the temperature at the anode and the four cavities, a fiber optic thermal monitoring system was borrowed and new fiber probes were purchased for our machine. At $2 / 3$ the system charge voltage, the temperature rise at the anode was $2.6 \mathrm{C}$ after 30 shots, which is consistent with our estimates. Since temperature of the LIA cores will rise much more slowly, anode cooling had to be installed before a core temperature change could be detected. A new water-cooled brass anode was installed.. Prolonged testing at $2 / 3$ the full charge voltage produced several cable breakdown problems which were repaired, but eventually, the cables will probably have to be replaced with higher breakdown strength cables for continuous operation. The longest burst tested was 3000 pulses at $30 \mathrm{~Hz}$. The temperature increase during this test confirmed our estimate for the heat load of the cavities, approximately $1 \mathrm{C}$ for 4000 pulses at full power.

On the advice of the LDRD renewal committee, we postponed the pursuit of the thermal retrofit and other accelerator issues in order to focus our attention on the PCSSbased modulator for the third and final year of this project. The spark-gap based modulator and the LIA was moved to building 963, where it would be available for testing with the PCSS based modulator. This move was reviewed and the new location in an existing radiation cell was approved by the pulsed power safety committee. 
4.2 PCSS Modulator Research and Development. Since PCSS is a developing technology, it is crucial to continue basic research into operation and fabrication of longer-lived devices. Many areas of PCSS research and development were supported, in part, by this LDRD. Approximately $20 \%$ of the funding for this project was devoted to supporting roughly $30 \%$ of the general PCSS research and development. A brief summary of some of the results which directly impact the PCSS-driven accelerator is provided in the following paragraph.

A fundamental model for low field avalanche carrier generation, called "collective impact ionization," was developed and published. Monte Carlo testing was initiated to check and expand this model. Several refinements of this model have been developed since the first model was published. Fundamental experiments were performed which produced temporal and spatially resolved current densities, spectra, and thermal distributions for the filaments which form during high gain switching. A silicon-nitride surface layer was used to reduce surface leakage and improve the "off-resistance" of the PCSS. A non-destructive method to characterize contacts to semi-insulating GaAs was developed and tested. PCSS driven LDAs were developed for triggering larger PCSS with sub-nanosecond optical pulses. An empirical model was developed which provides PCSS and laser diode array (LDA) device properties for arbitrary circuit modeling. Triggering systems and lasers were reduced in size and cost by several orders of magnitude. Precise positioning of optical trigger fibers using a long focal length microscope and an extended IR-sensitive, intensified CCD increased switch lifetime by producing diffuse filaments near the contacts. Over the course of this project, the lifetime of a PCSS conducting $10 \mathrm{~A}$ per filament was improved from less than 100,000 to more than 2 million pulses. Ion implanted switch contacts were developed and tested, and pdoped deep-diffused contacts were fabricated for improved switch lifetime. A sputtering technique was developed to produce $\mathrm{Au}: \mathrm{Be}$ contacts on our large 1-3.4 $\mathrm{cm}$ long PCSS.

Although most of our efforts during FY95 were directed toward the spark gap based modulator and the LIA, a substantial effort was also devoted to PCSS triggering experiments aimed at developing a preliminary design for the PCSS based pulser. Lifetime testing had shown that reasonable lifetimes could be obtained if the current per filament was held to less than $50 \mathrm{~A}$. A $100 \mathrm{kV}$, enclosed, $50 \mathrm{Ohm}$ strip-line circuit was used to test spot triggering schemes with multiple 200 micron diameter fiber optics. Our initial design called for four 3-4 cm long PCSS to drive each of the eight $50 \mathrm{Ohm}$ cables for the LIA.

The final design described in section 3.3 was proposed early in FY96. It reduced the electric field across the PCSS by combining all the modules into one large octagonal Blumlein. It also reduced the current required per PCSS by allowing more space for GaAs wafers perpendicular to the current flow. It simplified the optical trigger delivery system by placing the switches in each module along a single straight line. Finally, it reduced the system volume by a factor of six by using de-ionized water for the insulating dielectric instead of transformer oil. 
A thyratron-based pulse charging system, similar to the one described in sections 3.2 and 4.1, was assembled and tested to pulse charge the PCSS-based Blumlein. The voltage requirement of $250 \mathrm{kV}$ was approximately half that required for the spark-gap based PFL, because the multiple PCSS provide a very low inductance configuration which would not limit the rise time of the 3.12 Ohm sections of the Blumlein. The pulse transformer did not have to produce as high of voltage, it had to produce higher current than its spark-gap based counter-part. To deliver the same

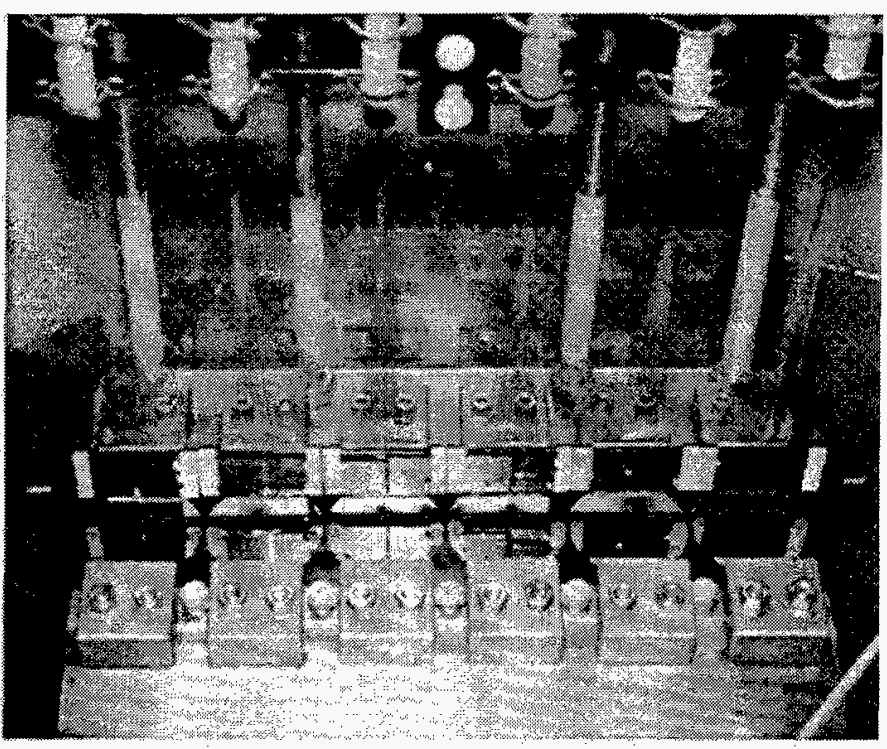

Figure 4.9. Optical trigger fibers are shown above the $6 \mathrm{GaAs}$ PCSS mounted on the top end of the Blumlein. (15" wide). This switching assembly is designed to drive $1 / 8^{\text {th }}$ of the PCSS pulser. total energy in the same amount of time to the Blumlein as was delivered to the PFL, more capacitance and higher charging currents currents were required.

To stay within budget, a Q-switched, Nd:YAG laser was withdrawn from storage and refurbished (cooling, electrical, and optical systems) to better than original specifications. The laser produces a Gaussian profile pulse which is injected to the entire bundle of trigger fibers. The uniformity of the optical pulses which are delivered to the output end of the fibers was measured and adjusted using a laser beam profiling system. Custom fiber optic bundles were ordered to trigger one Blumlein module (6 switches or $\sim 200$ filaments). Hardware was machined to hold the switches at the end of the Blumlein and to hold the fibers in straight lines along the contacts of the switches, where spot triggering was most effective. Figure 4.9 shows the holders, switches, and fibers for one Blumlein module. The parallel-plate Blumlein for one module was assembled from stainless steel sheet and threaded nylon rods to give output impedance of approximately 50 Ohms. A drawing of the Blumlein module and the switch holder is shown in figure 4.10 .

PCSS trigger testing was abruptly delayed when an apparent problem with the prolonged exposure of $\mathrm{GaAs}$ to deionized water appeared. A thin film was observed on the surface of GaAs wafers after being immersed for several days. The film, which was analyzed with Auger-electron spectroscopy, is $\mathrm{GaO}$. The missing arsenic was dissolved in the tank of deionized water. Samples of the water and the film were analyzed to determined the quantity of material which had reacted and its potential health hazard. Only a few angstroms of film had grown on the GaAs wafer during exposure to deionized water. The amount GaAs contained in the water sample was below the minimum level of detection which was well below the maximum exposure limit, so no health hazard was posed by the missing arsenic. Several potential ways to avoid this problem were 
proposed: 1) limit the exposure time of the GaAs switches to the deionized water, 2) coat the switches with a water-proof dielectric, 3) add chemicals to the water which slow the reaction without reducing the dielectric strength of the water, 4) change to another high dielectric constant liquid such as ethylene glycol, and 5) isolate the switches from the water dielectric with another interface. The problem was solved by building an interface to house the GaAs switches in fluorinert, which is a standard insulating dielectric that does not react with GaAs.

In general, multiple filament triggering was more difficult than anticipated from our previous testing. In addition, occasional breakdowns due to excessive current density in one switch would create shock waves which would fracture neighboring switches. We began to search for a better method to control the filament number and location. Previous testing with a homogenizer that produced a very fine grid of lines across the switch was reviewed, because this testing had occasionally produced a very precise set of straight filaments. Similar optical beam homogenizers were used to successfully trigger two of six wafers up to $150 \mathrm{kV}$ in the PCSS Blumlein module. The switches showed no apparent damage after 500 pulses, even though they conducted about $5 \mathrm{kA}$, or $150 \%$ of the current that they need to carry in the final configuration. Although the "homogenizers" were originally designed to produce uniform illumination from a "donut" shaped laser beam, 2-5 very straight filaments were initiated simultaneously on each wafer. Close inspection of the "homogenized" beam shows a mesh of very fine orthogonal lines which presumably are produced by facet edges on the homogenizer. It was suggested that these lines seed the filaments, causing them to form in very straight lines.

New experiments were initiated with higher impedance PFL configurations to reduce the total switch current and allow the exploration of a small number of line-triggered filaments. A beam splitter, a cylindrical lens, and neutral density filters were used to produce two tightly focused lines (approximately $500 \mu \mathrm{m}$ by $2 \mathrm{~cm}$ ) of equal energy at the surface of the switch. Consistent initiation of two filaments was demonstrated. Distinct, independent filaments were observed until the distance between the optical lines was less than $1 \mathrm{~mm}$. Reliable triggering was achieved at

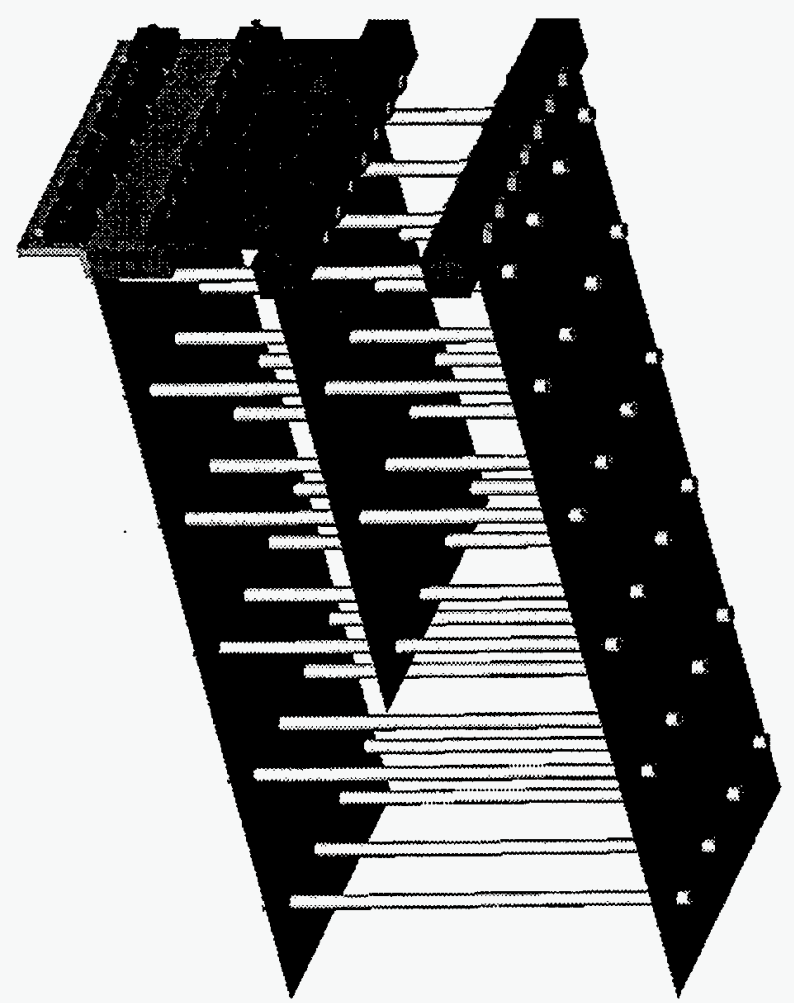

Figure 4.10. A single Blumlein module was assembled from stainless steel sheet and threaded nylon rods. The switch holder assembly is at the upper left corner. The module was roughly 36 inches tall and 15 inches wide. 
significantly lower voltages than had been obtained with spot triggering, indicating more efficient triggering. Triggering was observed at initial electric fields as low as the "lock-on" field which is defined as the field which is present across the switch during the sustaining phase (or "on" state) of high gain PCSS. This is evidence that very little field enhancement is required to initiate switching in this configuration. The switch was tested for several hours at $1 \mathrm{~Hz}$ or roughly 10,000 shots at currents of 200300 A per filament, which is $4-6$ times more current than we plan to switch per filament in the final design. Some degradation at the contacts was observed, but operational parameters of the switch were unchanged. The minimum energy required to trigger two filaments consistently at 30 $\mathrm{kV} / \mathrm{cm}$ was $1.6 \mu \mathrm{J}$. This implies $2.5 \mathrm{~mJ}$ of light would be required to trigger 1600 filaments for full power operation $(80 \mathrm{kA})$ at $50 \mathrm{~A}$ per filament. Our Nd:YAG laser produces $30-50 \mathrm{~mJ}$ per pulse of $532 \mathrm{~nm}$ light at modest settings.

A bank of step-rotated mirrors and a cylindrical lens was assembled to produce multiple (up to five) straight trigger lines across a single PCSS. An image obtained using four line-triggers is shown in figure 4.11. Consistent initiation was demonstrated with filaments

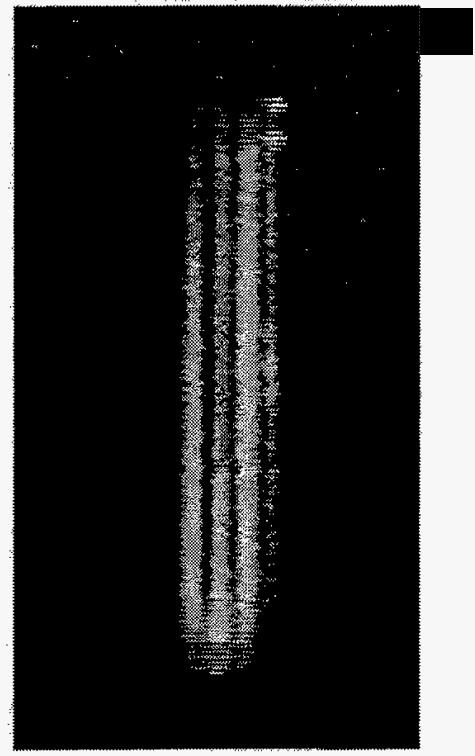

Figure 4.11. An image of four filaments across a 1.5 $\mathrm{cm}$ long GaAs PCSS was produced with 4 line-triggers. Precise control of the filament location and shape was achieved as these filaments carry 100-150 A each and are less than $1 \mathrm{~mm}$ apart. less than $1 \mathrm{~mm}$ apart carrying 100-150 A per filament. As with the two line triggering experiments, reliable triggering was achieved at significantly lower voltages than had been obtained with spot triggering, indicating more efficient triggering. Triggering was observed at initial electric fields as low as the "lock-on" field which is defined as the field which is present across the switch during the sustaining phase (or "on" state) of high gain PCSS. This is evidence that very little field enhancement is required to initiate switching in this configuration. The minimum energy required to trigger multiple filaments was

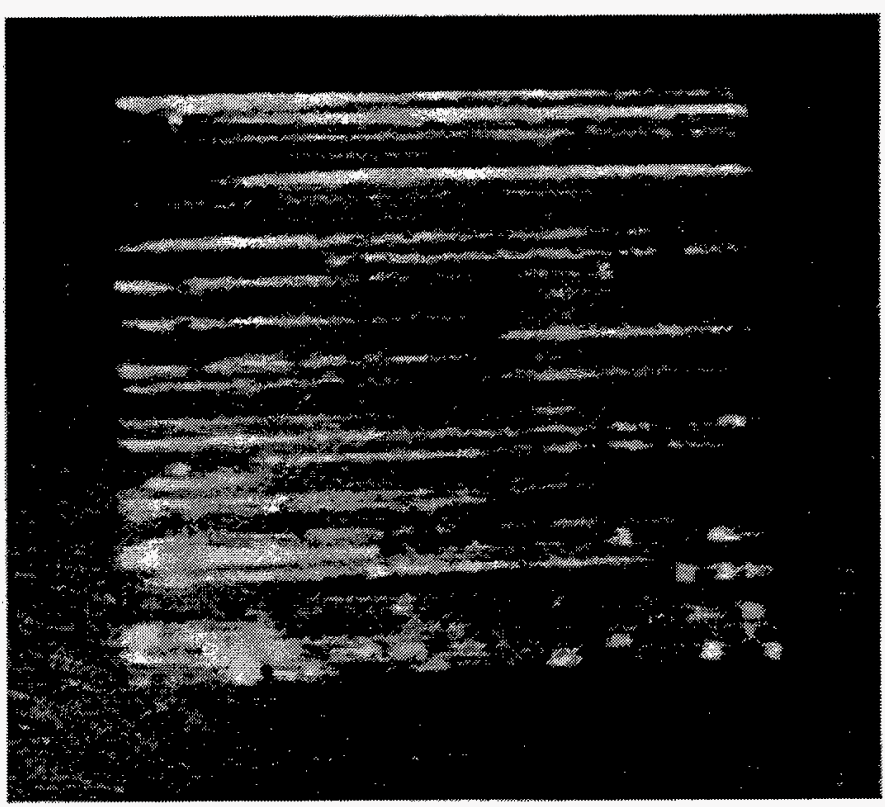

Figure 4.12. An image of 30 filaments across a $3.4 \mathrm{~cm}$ long GaAs PCSS. The filaments are triggered and viewed thru a layer of $1 \mathrm{~mm}$ diameter glass rods that are submersed in Fluorinert and $1 \mathrm{~mm}$ above the GaAs wafer. Total current is $380 \mathrm{~A}$ (13A/filament). 
approximately $2 \mu \mathrm{J}$ per filament. This implies $3.2 \mathrm{~mJ}$ of light would be required to trigger 1600 filaments for full power operation $(80 \mathrm{kA})$ at $50 \mathrm{~A}$ per filament, well below our trigger laser output of $30-50 \mathrm{~mJ}$ per pulse of $532 \mathrm{~nm}$ light at modest settings.

Next, glass rods were used as cylindrical lenses to focus the light from multiple fibers into relative sharp lines across the PCSS. By placing a layer of these rods very close to the GaAs surface, an array of lines could be obtained from the relatively uniform illumination emitted from a bundle of fibers. This produced thirty filaments on a single GaAs wafer (figure 4.12). The trigger pulses were transported to the switch in thirty-two $200 \mu \mathrm{m}$ diameter fibers. The average optical energy per fiber was $15 \mu \mathrm{J}$. This implies 25 $\mathrm{mJ}$ of light would be required to trigger 1600 filaments for full power operation $(80 \mathrm{kA})$ at $50 \mathrm{~A}$ per filament (still below our trigger laser goal of $30-50 \mathrm{~mJ}$ per pulse of $532 \mathrm{~nm}$ light). The fibers were grouped into a line of 8 bundles separated by $2 \mathrm{~mm}$ and $18 \mathrm{~cm}$ above the glass rods which were submerged in Fluorinert $1 \mathrm{~mm}$ above the surface of the GaAs wafer. Figure 4.12 shows a variation in the intensity along the individual filament lines. Part of this variation is caused by viewing the image of the filaments through the layer of glass rods. If the filaments do not form directly below the rods with respect to the camera, their emitted light is not directed toward the camera. Another contribution to the variation is that in some regions the filaments are formed deeper in the GaAs more of the emission is re-adsorbed by the GaAs.

Repetitive testing of line-triggered switches produced evidence of a new type of surface damage across the gap. Although, the operation of our standard $1.5 \mathrm{~cm}$ and $3 \mathrm{~cm}$ switches is still limited by damage near the contacts, the improved life-time PCSS may eventually be limited by the new type of damage. This damage appears exactly where the optical lines are formed to trigger the filaments. (See figure 4.13.) Pure optical damage is not likely at these intensities and no damage has been observed when the optical trigger is applied without charging the switches. The damage appears to accumulate gradually as we have not observed sudden changes with the video monitor. This type of damage is apparently correlated with the line-triggering technique, which focuses the optical trigger energy into $100 \mu \mathrm{m}$ wide lines at exactly the same location. After several thousand shots, damage lines start to form across the surface of the switches, where the filaments are being formed. Rotating the trigger lines, relative to the wafer crystal axis, showed that the damage stayed with the trigger lines and no

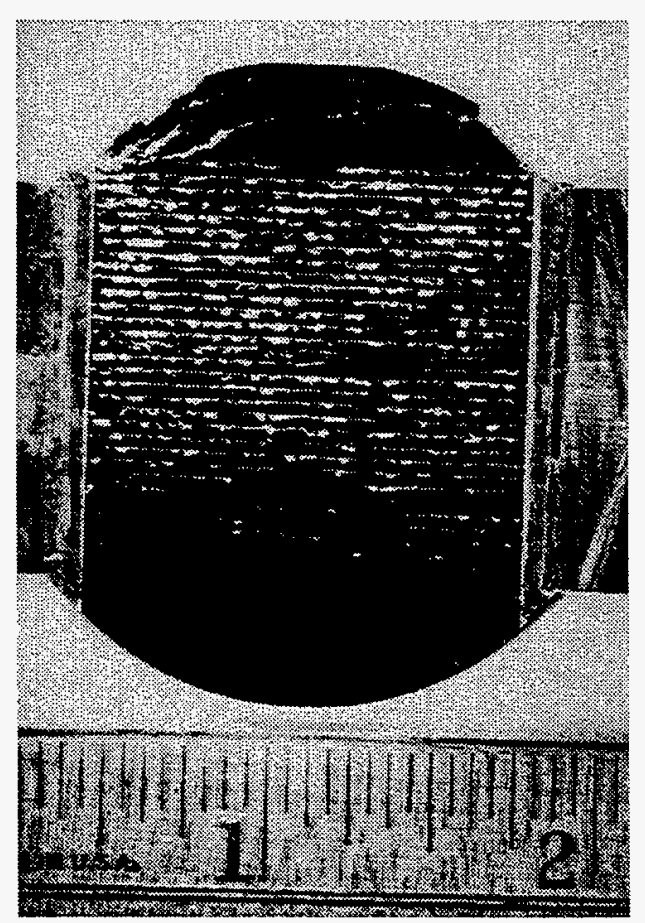

Figure 4.13. This photograph shows a new type of damage which accumulates gradually across the surface of a $3.4 \mathrm{~cm}$ long GaAs PCSS when current filaments are triggered repeatedly with $100 \mu \mathrm{m}$ wide optical lines in exactly the same location. Although, this damage does not presently limit the lifetime of the switches, it may become the limiting factor with switches. 


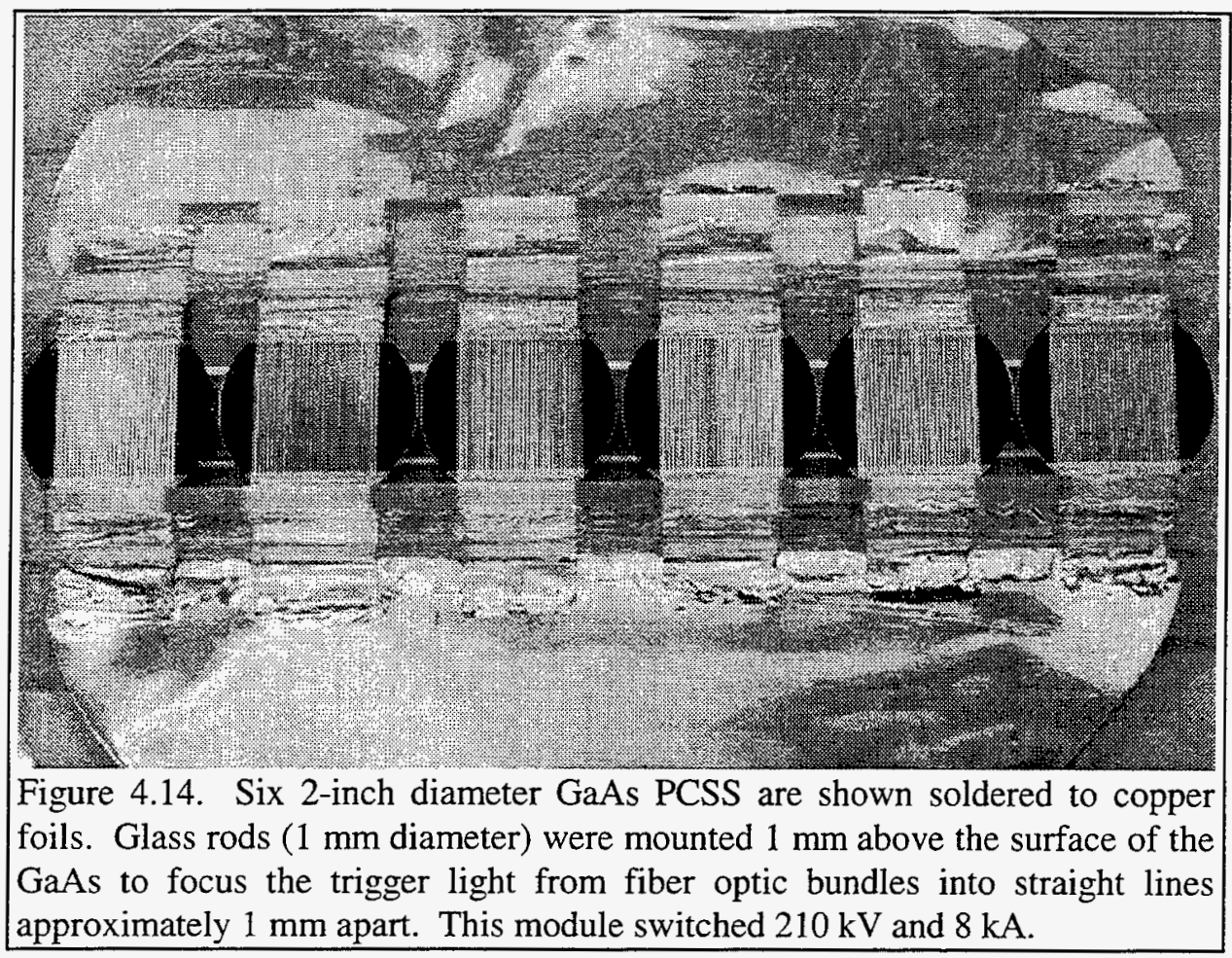

significant change in magnitude. Several questions have been raised which need further experimentation. Is the damage related to variations in current sharing? Would slightly lower current levels or improved trigger uniformity eliminate the damage? Could the damage be reduced by focusing the lines below the surface of the switch? Would defocussing the lines reduce this damage without degrading triggering? Would longer wavelength light, which penetrates more deeply into the GaAs reduce the damage?

Six 3.4-cm long switches were soldered to a metal foil assembly shown in figure 4.14. Layers of $1 \mathrm{~mm}$ glass rods were epoxied to the contacts so that they were approximately $1 \mathrm{~mm}$ above the surface of the switches. This entire assembly was mounted in a new switch holder for testing with a $50 \mathrm{Ohm}$ Blumlein module. The new holder insulates the switches with Fluorinert and isolates them from the water filled Blumlein. 192 optical fibers deliver the optical trigger energy to the switches in 8-fiber bundles. The light uniformly illuminates 180 glass rods to form $100 \mu \mathrm{m}$ wide lines $1 \mathrm{~mm}$ apart over the six switches. At full power, the switches will conduct $10 \mathrm{kA}$ with 33 filaments per switch, $50 \mathrm{~A}$ per filament, and $500 \mathrm{~A} / \mathrm{cm}$. Repetitive tests were be performed up to $210 \mathrm{kV}$ and approximately $8 \mathrm{kA}$. Further tests were postponed because the high sensitivity camera, which was required for precise alignment of the switches, rods, and fibers, was being modified at the manufacturer for higher speed gate operation. At $8 \mathrm{kA}$, if 30 filaments were formed on each switch (as shown in figure 4.13), this would be $44 \mathrm{~A} /$ filament or $440 \mathrm{~A}$ per $\mathrm{cm}$. The goal of this testing was to find the triggering configuration which gives the best PCSS lifetime with a reasonable amount of optical trigger energy (less than $50 \mathrm{~mJ}$ for the entire accelerator). The high sensitivity camera was needed to align the fiber optic triggers and verify the number and location of the filaments. Unfortunately, this project ended before these tests could be completed. 


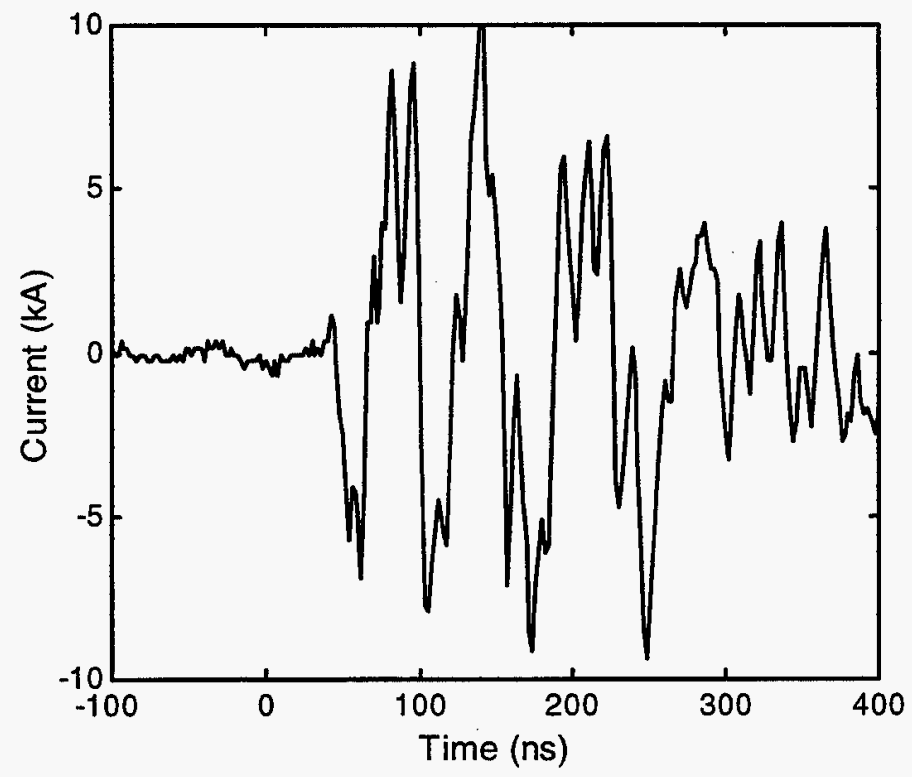

Figure 4.15. This waveform shows the current delivered by the 6-PCSS Blumlein to a nominal $50 \mathrm{Ohm}$ load. The ringing indicates an impedance mismatch where the line impedance is less than the load. More adjustments are required to match the Blumlein impedance to the load. This is a preliminary indication that the PCSS were switching between 5 and $10 \mathrm{kA}$. If there was a perfect match, the current in the PCSS would be twice the current at the load.

Figures 4.15 and 4.16 show the output current and charging voltage for one of the tests with the 6-switch module. These should be considered preliminary results because more effort is required to match the transmission line impedance to the load resistor, calibrate the derivative voltage monitors (not shown), and optimize the PCSS triggering. The complicated waveform shown in figure 4.15 can probably be improved in several ways, which are unrelated to PCSS operation. The simple carborundum load resistors have non-negligible inductance and voltage coefficients of resistance. They should be replaced by water resistors, which are more appropriate for this application. The spacing between Blumlein plates should be adjusted to optimize the impedance match and minimize ringing. The aspect ratio of this Blumlein, the edge fields, and potential current flow around the edges will all be improved or eliminated when the 8 modules are combined into one octagonal configuration. When all these improvements can be made, we expect to see a very "clean" single, flat-topped pulse, which is typical of well-matched PCSSbased systems. Our single switch tests on an enclosed tri-plate strip-line show very "clean" pulses with sub-nanosecond rise and fall times at up to $100 \mathrm{kV}$ (the limit of the test system). Assuming $80 \%$ LIA efficiency, full design requirements for the accelerator would be exceeded with 8 identical modules delivering $225 \mathrm{kV}$ and $9 \mathrm{kA}$. The PCSS Blumlein pulser is designed to deliver $250 \mathrm{kV}$ and $10 \mathrm{kA}$. 


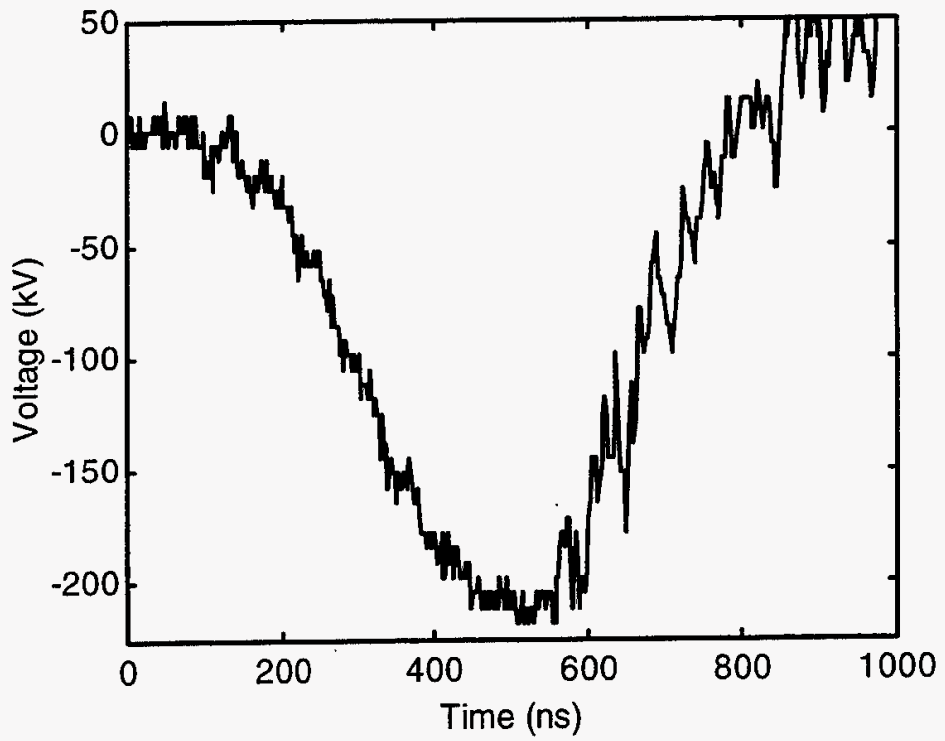

Figure 4.16. This waveforms shows the voltage to which the Blumlein was charged before triggering the PCSS. The system reached approximately $210 \mathrm{kV}$ when the switches were triggered (at time $560 \mathrm{~ns}$ ). The charging system was designed to drive all 8 modules, so switching 1 module (6 PCSS) does not have a very large effect on the charging voltage. 


\section{CONCLUSIONS}

The goal of this project was a small, $700 \mathrm{kV}$ accelerator which can produce $7 \mathrm{kA}$ particle beams with pulse lengths of $10-30 \mathrm{~ns}$ at rates up to $50 \mathrm{~Hz}$ for military and commercial applications in counter-proliferation, materials processing, radiography, and sterilization. Two switching technologies were tested: (1) spark gaps and (2) high gain photoconductive semiconductor switches (PCSSs). The spark gap based system switches a low impedance pulse forming line (PFL), which drives four small linear induction accelerator (LIA) cavities. In FY96, a field enhanced diode was tested, and the LIA was modified to operate continuously at $50 \mathrm{~Hz}$. In FY97, the PCSS module was assembled and tested to drive $50 \mathrm{Ohms}, 1 / 8$ th of the LIA. The development of a PCSS switching module, which can switch $10 \mathrm{kA}$ of current in 198 current filaments on six 2-inch GaAs wafers, proved more difficult than expected. At the advice of the pulse power review committee, research was focused on making one module trigger very accurately rather than initiating construction of the other modules required to drive the entire accelerator. In FY97, we succeeded in producing 30 consistent current filaments on one wafer and initiated testing on 6 wafers in parallel at $210 \mathrm{kV}$ and $8 \mathrm{kA}(440 \mathrm{~A} / \mathrm{cm})$. Before completing, these tests, the optical delivery system needs to be adjusted to maximize the number of current filaments produced in the switches. The LIA was moved into place for connection to the PCSS system. However, further resources will be necessary to assemble the other modules and test the four accelerator cavities with the eight PCSSbased modulators. The LIA is also available to test other emerging technologies, such as magnetic switches. The advantages of the PCSS are lower inductance and the design flexibility of distributed switching due to their extremely precise triggering. For the LIA and the diode, this translates to faster rise-times, more rectangular pulses, the capability of shorter pulses, and potentially higher diode efficiency. 
Distribution:

\begin{tabular}{|c|c|c|}
\hline 1 & MS 9018 & Central Technical Files, 8940-2 \\
\hline 2 & MS 0899 & Technical Library, 4916 \\
\hline 1 & MS 0188 & C. E. Meyers, LDRD program office, 4523 \\
\hline 2 & MS 0619 & $\begin{array}{l}\text { Review \& Approval Desk, } 12690 \\
\text { For DOE/OSTI }\end{array}$ \\
\hline 1 & MS 0151 & Gerold Yonas, 9000 \\
\hline 1 & MS 0603 & Albert Baca, 1314 \\
\hline 1 & MS 0603 & Tom Plut, 1314 \\
\hline 1 & MS 0959 & Cathy Sifford, 1471 \\
\hline 1 & MS 0959 & Juan Romero, 1471 \\
\hline 1 & MS 0820 & Harry Hjalmarson, 9232 \\
\hline 2 & MS 1165 & Joe Polito, 9300 \\
\hline 2 & MS 1153 & Malcolm Buttram, 9323 \\
\hline 1 & MS 1153 & Steve Babcock, 9323 \\
\hline 1 & MS 1153 & Darwin Brown, 9323 \\
\hline 1 & MS 1153 & Gary Denison, 9323 \\
\hline 1 & MS 1153 & Wes Helgeson, 9323 \\
\hline 1 & MS 1153 & Guillermo Loubriel, 9323 \\
\hline 1 & MS 1153 & Alan Mar, 9323 \\
\hline 1 & MS 1153 & Martin O'Malley, 9323 \\
\hline 1 & MS 1153 & Ron Pate, 9323 \\
\hline 1 & MS 1153 & Larry Rinehart, 9323 \\
\hline 1 & MS 1153 & Gerry Rohwein, 9323 \\
\hline 1 & MS 1153 & Mitchell Ruebush, 9323 \\
\hline 20 & MS 1153 & Fred Zutavern, 9323 \\
\hline 2 & MS 1190 & Don Cook, 9500 \\
\hline 1 & MS 1188 & Roy Hamil, 9512 \\
\hline 1 & MS 1188 & Dave Bliss, 9512 \\
\hline 1 & MS 1188 & Stewart Cameron, 9512 \\
\hline 2 & MS 1182 & Bob Turman, 9521 \\
\hline 1 & MS 1182 & Ron Kay, 9512 \\
\hline
\end{tabular}


M98005264

||||||||||||||||

Report Number (14)_SAND-. $98-0898$

Publ. Date (11) 199804

Sponsor Code (18) DOEJP; DOETER

UC Category (19) $\frac{U C-404 ; 4 C-406 ; 6 c-40 j}{4 C-426 ; 4 c-704 ; 4 C-715}$ (i8) DOE/ER; DOE/ER; DOE/ER' DOE/ER;
DOE/DP; DOE/DP, XF

(19) Uc-404; Uc-406; uc-410; uc-426;

$4 C-704 ; 4 C-715, D O E / E R$

19980622083

DIIC QUALTIY DVQPECTHD I 